\title{
Article
}

\section{A review on the two-phase pressure drop characteristics in helically coiled tubes}

\author{
Fsadni, A and Whitty, J \\ Available at http://clok.uclan.ac.uk/13844/
}

Fsadni, A ORCID: 0000-0003-3047-2714 and Whitty, J ORCID: 0000-00031002-5271 (2016) A review on the two-phase pressure drop characteristics in helically coiled tubes. Applied Thermal Engineering, 103 . pp. 616-638. ISSN 1359-4311

It is advisable to refer to the publisher's version if you intend to cite from the work. http://dx.doi.org/10.1016/j.applthermaleng.2016.04.125

For more information about UCLan's research in this area go to http://www.uclan.ac.uk/researchgroups/ and search for < name of research Group>.

For information about Research generally at UCLan please go to http://www.uclan.ac.uk/research/

All outputs in CLoK are protected by Intellectual Property Rights law, including Copyright law. Copyright, IPR and Moral Rights for the works on this site are retained by the individual authors and/or other copyright owners. Terms and conditions for use of this material are defined in the policies page.

\section{CLoK}

Central Lancashire online Knowledge www.clok.uclan.ac.uk

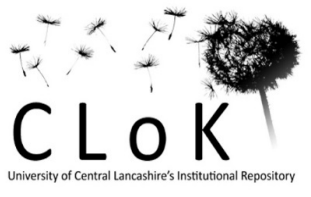




\section{Manuscript details}

Manuscript number

Title

Article type

Abstract

HMT_2016_438

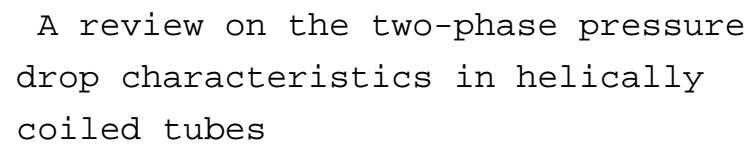


Two-phase flow; curved tubes; frictional

pressure drop; flow boiling; nanofluids

Corresponding Author

Corresponding Author's Institution

Order of Authors

Suggested reviewers
Andrew Fsadni

University of Central Lancashire

Andrew Fsadni, Justin Whitty

Mohamed Basuny, Bengt Sunden, Harry Edmar Schulz

\section{Submission files included in this PDF}

File Type

Cover Letter

Conflict of Interest

Title page with author details

Highlights

Manuscript
File Name

Cover Letter_A Fsadni_08_02_16.pdf

Author Declaration_A Fsadni_08_02_16.pdf

Title Page_Review Paper_Helical Coils_Pressure Drop_08_

Highlights_Review Paper_Helical Coils_Pressure Drop_08_

Manuscript_Review paper_Pressure Drop_Helical Coils_08

To view all the submission files, including those not included in the PDF, click on the manuscript title on your EVISE Homepage, then click 'Download zip file'. 
Room: KM 124

School of Engineering

University of Central Lancashire, Preston

UK, PR1 2HE

The Editor,

International Journal of Heat and Mass Transfer, Elsevier Publishing

$8^{\text {th }}$ February 2016

Dear Prof. Rose,

I would like to submit the attached manuscript entitled: 'A review on the two-phase pressure drop characteristics in helically coiled tubes' for publication in the International Journal of Heat and Mass Transfer. This research complements our earlier paper entitled: 'A review on the two-phase heat transfer characteristics in helically coiled tube heat exchangers'. For the purposes of the current submission, I have selected the Elsevier 'Your Paper Your Way' submission process.

I thank you for taking the time to consider this request and I look forward to hearing from you in due course.

Yours sincerely,

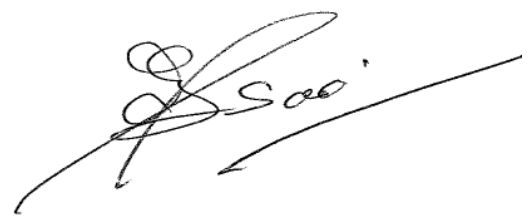

Dr. Andrew M. Fsadni

PhD, MSc, MBA, BEng (Hons), EUR ING, FHEA, CEng, MIMechE

Lecturer, School of Engineering,

University of Central Lancashire, UK 


\section{Author Declaration}

I wish to confirm that there are no known conflicts of interest associated with this publication and there has been no significant financial support for this work that could have influenced its outcome.

I confirm that Dr Justin P.M. Whitty and the undersigned are the sole authors of the manuscript and therefore, there are no other persons who satisfied the criteria for authorship but are not listed.

I confirm that, due consideration has been given to the protection of intellectual property associated with this work and that there are no impediments to publication, including the timing of publication, with respect to intellectual property. In so doing, I confirm that I have followed the regulations of my institution concerning intellectual property.

I understand that as a Corresponding Author, I am the sole contact for the Editorial process. I confirm that I have provided a current, correct email address which is accessible by myself as the Corresponding Author and which has been configured to accept emails from The International Journal of Heat and Mass Transfer.

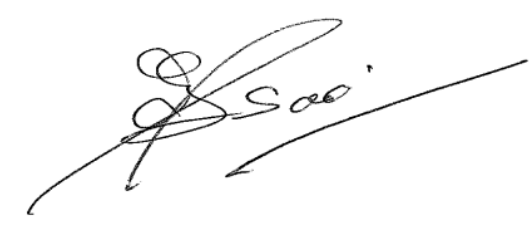

Dr Andrew M. Fsadni

$08^{\text {th }}$ February 2016 
Title: A review on the two-phase pressure drop characteristics in helically coiled tubes

Authors: Andrew Michael Fsadni*, Justin P.M. Whitty

*Corresponding author

Contact details:

Address: University of Central Lancashire, School of Engineering, Rm. KM124, Preston, UK, PR1 2HE

Email: $\underline{\text { afsadni@uclan.ac.uk }}$

Tel: +441772893812 


\section{Highlights}

- Detailed review on the two-phase pressure drop characteristics and correlations

- Impact of curvature on the flow boiling frictional pressure drop is not significant

- Nanofluids' impact on the pressure drop is significant

- There is a significant gap in literature in the field of frictional drag reduction 


\title{
A review on the two-phase pressure drop characteristics in helically coiled tubes
}

\begin{abstract}
Due to their compact design, ease of manufacture and enhanced heat transfer and fluid mixing properties, helically coiled tubes are widely used in a variety of industries and applications. In fact, helical tubes are the most popular from the family of coiled tube heat exchangers. This review summarises and critically reviews the studies reported in the pertinent literature on the pressure drop characteristics of two-phase flow in helically coiled tubes. The main findings and correlations for the frictional two-phase pressure drops due to: steam-water flow boiling, R-134a evaporation and condensation, air-water two-phase flow and nanofluid flows are reviewed. Therefore, the purpose of this study is to provide researchers in academia and industry with a practical summary of the relevant correlations and supporting theory for the calculation of the two-phase pressure drop in helically coiled tubes. A significant scope for further research was also identified in the fields of: air-water bubbly flow and nanofluid two phase and three-phase flows in helically coiled tubes.
\end{abstract}

Keywords: Two-phase flow; curved tubes; frictional pressure drop; flow boiling; nanofluids

\section{Introduction}

Due to their compact design, ease of manufacture and high efficiency in heat and mass transfer, helically coiled tubes are widely used in a number of industries and processes such as in the food, nuclear, aerospace and power generation industries and in heat recovery, refrigeration, space heating and air-conditioning processes. Due to the formation of a secondary flow, which inherently enhances the mixing of the fluid, helically coiled tube heat exchangers are known to yield improved heat transfer characteristics when compared to straight tube heat exchangers. The secondary flow is perpendicular to the axial fluid direction and reduces the thickness of the thermal boundary layer. Goering et al. [1] estimated the secondary flow to account for circa $16-20 \%$ of the mean fluid flow velocity. This phenomenon finds its origins in the centrifugal force due to the curvature of the coil structure and is more evident with laminar flow due to the limited fluid mixing in straight tube laminar flow [2,3]. However, for single and two-phase flows, the secondary flow could also result in an undesirable increase in the frictional pressure drop over that of straight tubes. For air-water two-phase flow in helically coiled tubes, Akagawa et al. [4] reported frictional pressure drops in the range of 1.1 to 1.5 times greater than those in straight tubes, ceteris paribus. Therefore, the performance of helical coils is also a function of the geometry and design parameters such as the tube diameter and the pitch (Fig. 1) as well as the resultant pressure drop. Through their study on the investigation of the heat transfer characteristics with the addition of multi-walled carbon nanotubes nanoparticles to oil, Fakoor-Pakdaman et al. [5] reported their results in terms of the Performance Index (PI), given in Eq. (1). This captures the simultaneous effects of heat transfer and two-phase pressure drop with the use of nanofluids and helical tubes on the overall performance of the heat exchanger. When the performance index is greater than unity, the PI implies that the benefits gained through enhanced heat transfer coefficients outweigh the effects of larger pressure drops as a result of the nanoparticles and helical tubes.

$$
\eta=\frac{\frac{h^{*}}{h_{s t}}}{\frac{\Delta P^{*}}{\Delta P_{s t}}}
$$


where $h^{*}$ is the mean heat transfer coefficient after the application of enhancement techniques, $h_{s t}$ is the mean heat transfer coefficient in a straight tube with the base fluid only, $\Delta P^{*}$ is the mean pressure drop after the application of enhancement techniques and $\Delta P_{s t}$ is the mean pressure drop inside a straight tube with the base fluid only.

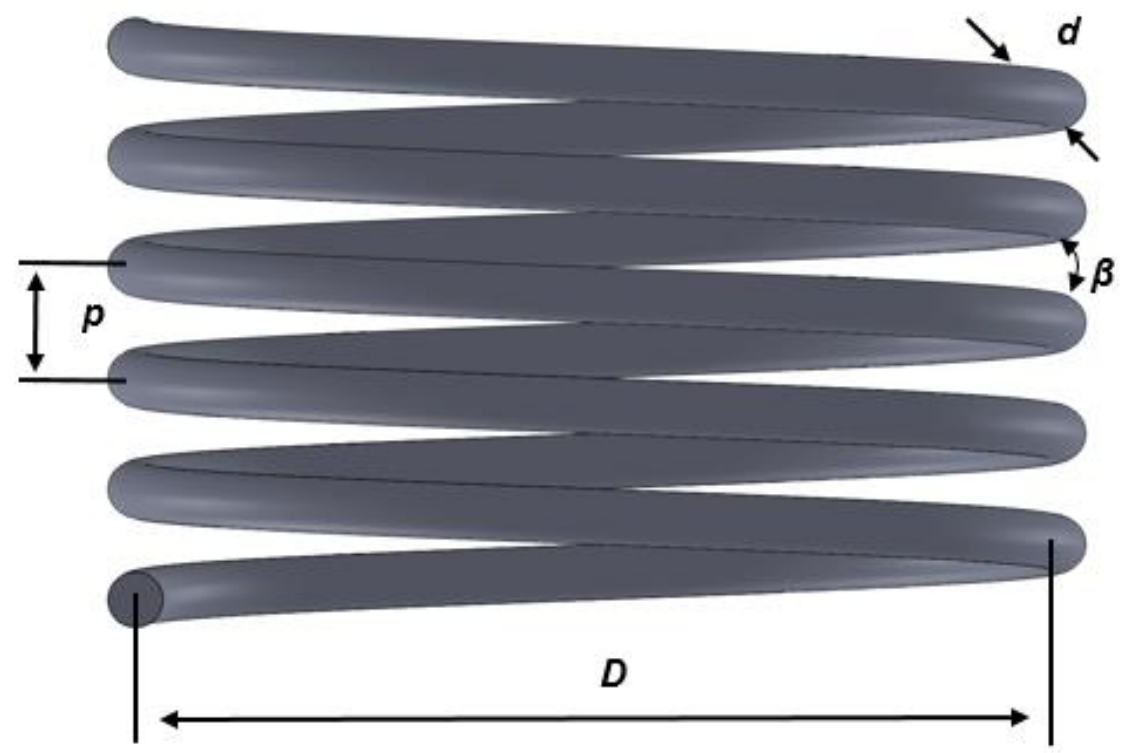

Figure 1: Schematic representation of helical pipe characteristics

The pertinent literature, presents a considerable number of widely cited studies on the pressure drop for single-phase flow in helically coiled tubes [6,7]. A lesser number of studies have investigated the two-phase pressure drop characteristics in helically coiled tubes. Whilst being more relevant to real-life engineering systems, when compared to single-phase flow, two-phase flow is significantly more complex due to the combination of the three forces governing the flow regime, these being the: inertia, liquid gravity and centrifugal forces [8]. Numerous studies investigated the two-phase frictional pressure drop with steam-water flow boiling [9,10], R-134a refrigerant flows [11,12] and air-water flows [4] whilst more recently, a number of authors investigated the application of nanofluids $[13,14]$ in helically coiled tubes through experimental and computational studies. Mandal and Das [15] and Murai et al. [16] reported that the phase with the lower density is subjected to a smaller centrifugal force which forces the lighter phase to shift towards the inner side of the coil's wall. However, Saffari et al. [17] reported that for bubbly flows at elevated Reynolds numbers and characterised by small bubble diameters $(b<0.5 \mathrm{~mm})$, the enhanced fluid mixing could result in a quasi-homogenous distribution of the secondary phase. This draws an analogy to similar investigations with nanofluids where no significant phase separation was reported [18].

A recent development in the field of bubbly air-water two-phase flow has resulted in the injection of microbubbles in the flow to achieve a reduction in the system frictional pressure drop. Hitherto, this research has focused on the injection of air bubbles over flat plates and in straight tubes with a minimal consideration for the investigation of the pressure drop reduction in coiled tubes. When investigating the drag reduction inside a channel Nouri et al. [19] reported that bubble injection can be used to decrease the flow transfer costs. In fact, they reported a 35\% reduction in the pressure drop in turbulent upward pipe flow with the maximum experimental volumetric void fraction of $9 \%$. This is attributed to the congregation of the larger bubbles at the pipe wall. To the best of the authors' knowledge, the sole investigation with 
coiled tubes was done by Saffari et al. [17] who reported an increase in the magnitude of drag reduction with increasing volumetric void fraction and decreasing Reynolds and Dean Numbers. These conclusions contrast to the findings reported by the majority of investigations on air-water bubbly flows, where two-phase pressure drop multipliers in excess of unity were reported $[20,8]$. The pertinent literature also presents some controversy through conflicting results on the impact of nanoparticles on the frictional pressure drop in helically coiled tubes. In fact, whereas the majority of investigations reported a rise in the pressure drop with the particle concentration [21, 22], some investigations concluded that the opposite effect could occur [23].

Naphon and Wongwises [24] briefly reviewed the single and two-phase flow and pressure drop characteristics in curved tubes. However, their review was principally focused on the single-phase flow characteristics and hence they failed to adequately review the pertinent literature for two-phase flow. Therefore, to the best of the authors' knowledge the open literature does not present comprehensive reviews on the pressure drop characteristics of twophase flow in helically coiled tube heat exchangers. The current study will therefore present a review of the pertinent literature on the two-phase frictional pressure drop characteristics and correlations in helically coiled tubes. It is the authors' hope that this review will be useful to both academics and industry based engineers through the provision of a comprehensive report on the relevant current knowledge and controversies in literature. The present study will also identify areas for further research.

\subsection{Research Methods}

Experimental and numerical methods were used to investigate the pressure drop characteristics in helically coiled tubes. Fig. 2 presents a schematic diagram of the test facility developed by Guo et al. [25] and Cioncolini et al. [26] for the investigation of the steam-water flow boiling pressure drop in helically coiled tubes at varying operating system parameters such as

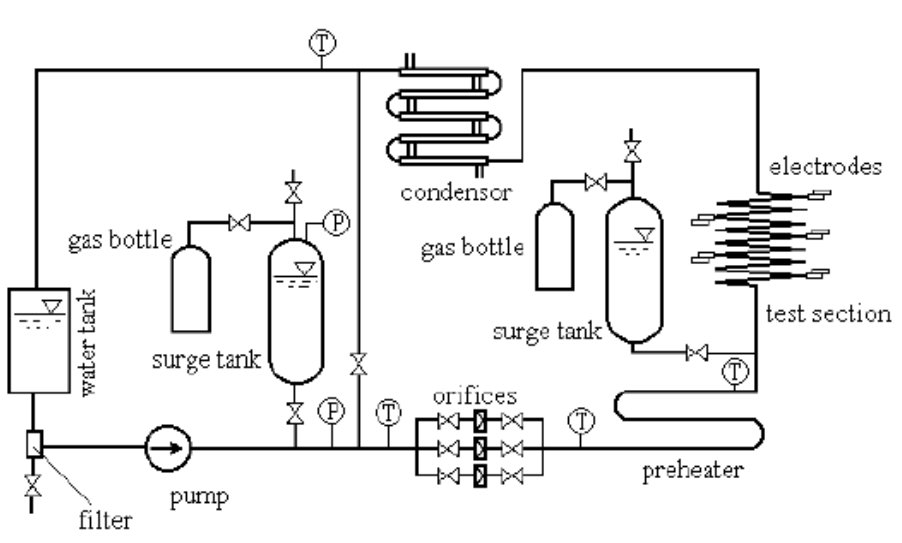

Test Rig

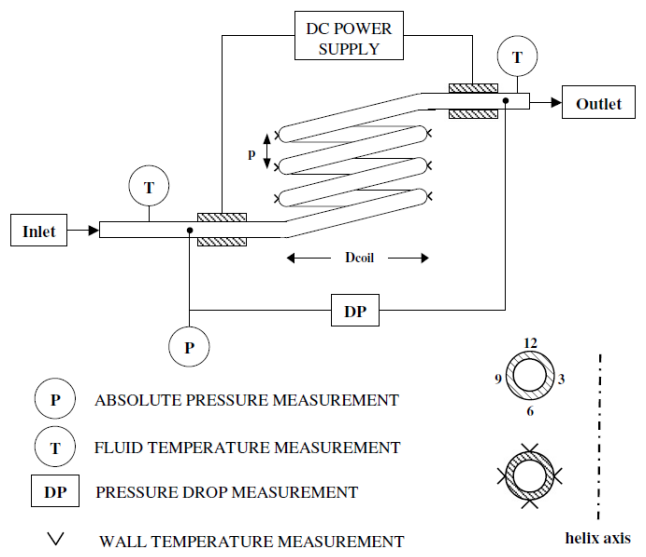

Test Section

Figure 2: Schematic diagram of the typical experimental test rig for the investigation of the flow boiling two-phase pressure drop in helically coiled tubes (Guo et al. (2001b) [25] Fig. 1) and the typical test section (Cioncolini et al. [26], Fig. 2)

the pressure, heat and mass fluxes. This setup is typical for most experimental studies in this field of study. An experimental uncertainty of $2.5 \%$ was reported by Cioncolini et al. for their two-phase pressure drop measurements.

As illustrated in Fig. 2, the typical experimental setup for the investigation of the flow boiling two-phase pressure drop characteristics in helically coiled tubes included a centrifugal 
pump for maintaining the system mass flow rate. Before entering the test section, the working fluid was heated to a subcooled state through the use of the pre-heater. The system bulk fluid flow rates were typically controlled by the system circulation pump. Stainless steel $[25,27,28]$ was used for the test section, which was thermally insulated to minimise the heat losses to the environment. The majority of the studies reviewed in this paper used the electrical direct heating method to heat the test section whilst, armoured K-type thermocouples were typically used to measure the bulk fluid temperature along the test section. K-type thermocouples, welded to the outside surface of the tube, were also used to measure the tube's wall temperature. These thermocouples were electrically insulated in order to avoid the effects of the heating electrical currents on it. Pressure sensors, installed at the return and flow ends of the helically coiled tube, measured the total two-phase pressure drop whilst a water cooled condenser condensed the steam or refrigerant vapour after the test section. The signals from the various measuring sensors were channelled to a data acquisition system for data monitoring and processing purposes.

All the numerical investigations reviewed in the current study were developed through the use of a commercially available computational fluid dynamics package, namely ANSYS Fluent $[22,29]$. The majority of authors validated their experimental and numerical methods through the comparison of the single-phase frictional pressure drop data with widely cited single-phase correlations for helically coiled tubes, such as those given by Ito [30] and Mishra and Gupta [31].

\section{Flow boiling heat transfer coefficient}

\subsection{Steam and Water}

A number of correlations are presented in the open literature for the calculation of the flow boiling pressure drop multiplier in helically coiled tubes for a wide range of system parameters. The reviewed correlations are summarised in Table 1 according to the key parameters governing their applications. The total two-phase pressure drop can be broken down into three component pressure drops these being the frictional, gravitational and the momentum pressure drops (Eqs.2-5) [32]. Many researchers have presented the two-phase frictional pressure drop as a function of the pressure drop multiplier and the single-phase frictional pressure drop as given in Eq. (3).

$$
\Delta P_{\text {total }, T P}=\Delta P_{f, T P}+\Delta P_{\text {grav }}+\Delta P_{a c c}
$$

$\Delta P_{f, T P}=\Delta P_{l} \emptyset_{l}^{2}$

where $\Delta P_{f, T P}$ is the two-phase flow frictional pressure drop of helical coils, and $\Delta P_{l}$ is the frictional pressure drop of the single-phase fluid flowing through the tube with the assumption that only liquid flows through the tube. Many authors have used the single-phase friction factor numerical model given by Ito [6] to calculate the latter pressure drop.

$$
\Delta P_{\text {grav }}=\left[\frac{g H}{x_{\text {exit }}-x_{\text {inlet }}}\right]\left[\frac{\ln \left(1+x\left(\frac{\rho_{l}}{\rho_{g}}-1\right)\right)}{\left(\frac{1}{\rho_{g}}-\frac{1}{\rho_{l}}\right)}\right]_{\text {exit }}-\left[\frac{g H}{x_{\text {exit }}-x_{\text {inlet }}}\right]\left[\frac{\ln \left(1+x\left(\frac{\rho_{l}}{\rho_{g}}-1\right)\right)}{\left(\frac{1}{\rho_{g}}-\frac{1}{\rho_{l}}\right)}\right]_{\text {in }}
$$

$$
\Delta P_{a c c, T P}=G^{2}\left\{\left[\frac{1-x}{\rho_{l}}+\frac{x}{\rho_{g}}\right]_{e x i t}-\left[\frac{1-x}{\rho_{l}}+\frac{x}{\rho_{v}}\right]_{i n}\right\}
$$


There appears to be a general agreement amongst the pertinent studies reviewed that the two-phase flow boiling frictional pressure drop increases with the vapour quality and mass flux whilst it decreases with higher system pressures. The curvature ratio does not appear to have a significant influence on the two-phase flow boiling frictional pressure drop multiplier whilst there is some controversy surrounding the influence of the coil orientation and heat flux. Over the past 50 years, the application of numerical models to predict the flow boiling frictional pressure drop in coiled tubes has highlighted the general difficulty in predicting the flow characteristics of two-phase flow. Therefore, many authors have presented their own empirical or semi-empirical models, or correlated existing models to fit their experimental data. The earliest investigations on the flow boiling frictional pressure drop in helically coiled tubes [10, 28,33 ] correlated the experimental data with well-known numerical models for the two-phase frictional pressure drop multiplier for straight tubes as given by Lockhart and Martinelli [34], Martinelli and Nelson [35] and Chen [36]. The latter are typically a function of the Lockhart and Martinelli parameter, which, in turn, is a function of the vapour quality and the densities and viscosities of the liquid and gas phases.

Kozeki et al. [28] reported that at the flow boiling region, the frictional pressure drop was circa 70 percent larger than that predicted by the Martinelli and Nelson numerical model for two-phase flow in straight tubes. The higher frictional pressure drop was attributed to the secondary flow phenomenon in the vapour core region where the largest influence was recorded at low pressures and high Reynolds numbers. Such results are in agreement with more recent studies reported by Guo et al. [37] and Santini et al. [38] who concluded that the frictional pressure drop decreases with higher system pressures (Fig.3). This is due to the resultant lower specific volume which in turn yields a lower mixture velocity. Nariai et al. [10] also reported that the effects of the flow boiling phenomena on the frictional pressure drop are not distinct in the fluid conditions.

The influence of the vapour quality on the frictional pressure drop does not appear to be uniform over the complete vapour quality range. Guo et al. [37] and Zhao et al. [27] reported that at vapour qualities below 0.3 , the frictional pressure drop increased significantly with the vapour quality whilst at higher qualities this increase was less significant. Santini et al. also reported that the increase in the frictional pressure drop stopped at a vapour quality of 0.8 and subsequently decreased as the quality approached unity. They attributed this phenomenon to the annular flow regime where the liquid film becomes too thin to maintain the interface waves. No other authors have reported similar results for helically coiled tubes and therefore, the latter results can be classified as indeterminate and hence, present ample scope for further investigations.

Bi et al. [32] and Zhao et al. [27] are the sole authors to report that the heat flux does not have a significant impact on the frictional pressure drop. However, more recently, Cioncolini et al. [26] reported that the heating effects resulted in an influence on the frictional pressure drop and hence, their correlation for the frictional pressure drop multiplier is also a function of the system heat flux. They attributed this influence to the interface between the liquid film and the vapour core being dependent on the evaporation and nucleation processes.

Bi et al. [32] and Guo et al. [37] are the sole authors who investigated the flow boiling frictional pressure drop as a function of the coil orientation. However, whilst the former reported that the coil orientation had no significant impact on the two-phase frictional pressure drop, the latter reported distinctly different results. Guo et al. reported that the horizontal coils resulted in the smallest frictional pressure drop whilst the 45 degree, downwards inclined coils resulted in the largest measured pressure drop (70\% higher than that measured for the horizontal orientation). The frictional pressure drop for the vertical coil was between that measured for the horizontal and the inclined orientations. Guo et al. attributed these results to the variation in the secondary flow regime with the tube orientation. The authors of the present 
study cannot adequately address the differences in these two results as the system parameters for both studies were distinctly similar. However, drawing on the conclusions reported by Santini et al. [38] regarding the influence of the system pressure on the pressure drop, the significantly higher system pressure used in Bi et al.'s investigation could suggest that at high system pressures, the flow boiling frictional pressure drop is quasi-independent of the coil orientation.

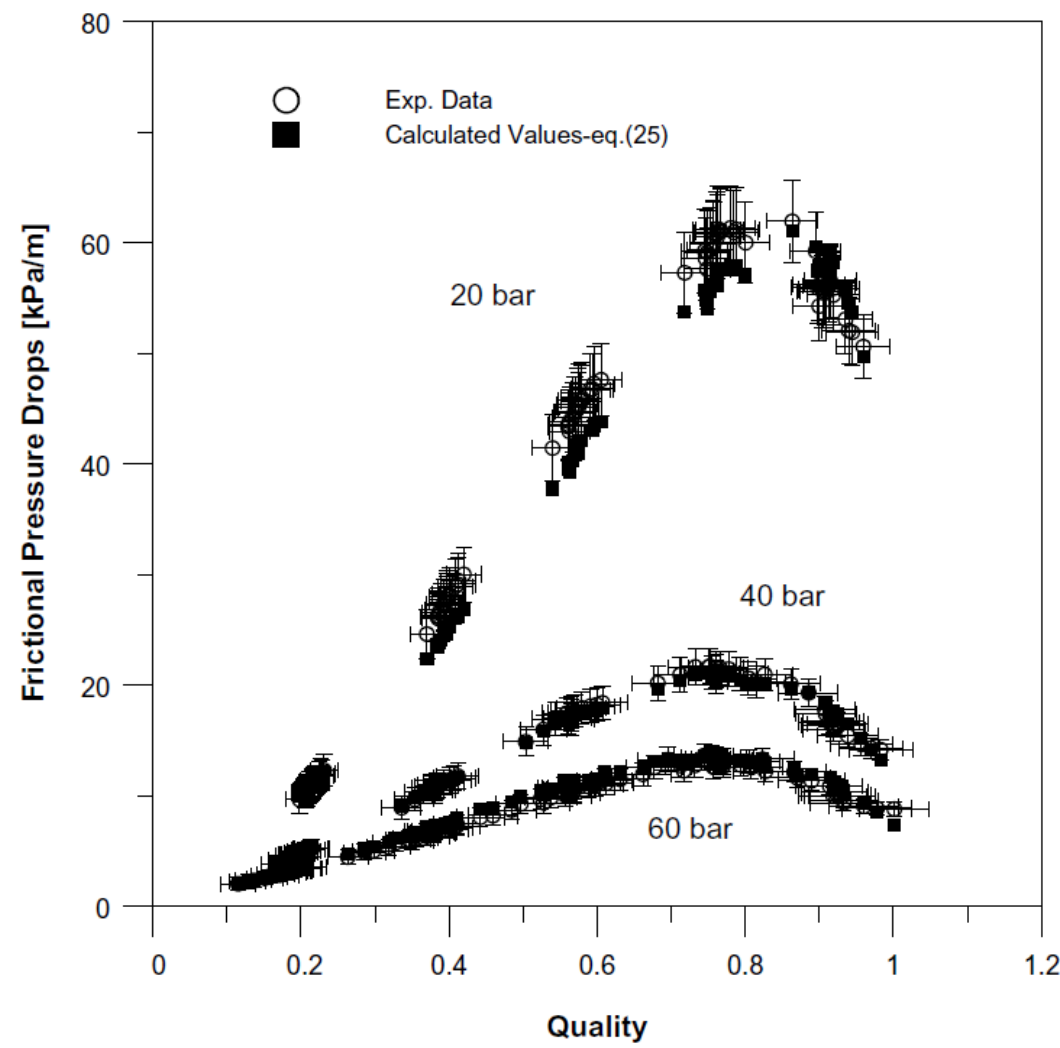

Figure 3: Experimental and predicted (Equation for $\Delta P_{f, T P}$ in Table 1) two-phase flow frictional pressure drop with system pressure and vapour quality at a constant mass flux of $600 \mathrm{~kg} / \mathrm{m}^{2} \mathrm{~s}$ (Santini et al. [38], Fig. 7)

\begin{tabular}{|c|c|c|c|c|}
\hline \multicolumn{5}{|c|}{$\begin{array}{l}\text { Correlations derived from the widely used two-phase flow pressure drop correlations for straight tubes } \\
\qquad(P<3.5 \mathrm{MPa} \& d \geq 12 \mathrm{~mm})\end{array}$} \\
\hline Authors & $\begin{array}{l}\text { Helical coil } \\
\text { design } \\
\text { parameters }\end{array}$ & $\begin{array}{c}\text { Principal } \\
\text { experimental } \\
\text { parameters }\end{array}$ & $\begin{array}{l}\text { Steam } \\
\text { quality }\end{array}$ & $\begin{array}{l}\text { Main conclusions, proposed correlation and } \\
\text { mean error }\end{array}$ \\
\hline $\begin{array}{c}\text { Owhadi et } \\
\text { al. (1968) } \\
{[33]}\end{array}$ & $\begin{array}{c}15.9 \mathrm{~mm} \mathrm{OD} \\
12.5 \mathrm{~mm} \mathrm{ID} \\
250<D<527 \\
\text { Vertical }\end{array}$ & $\begin{array}{c}0.024<\delta<0.05 \\
P=0.1 \mathrm{MPa} \\
60<q<256 \\
0.0097<\dot{m}<0.039 \\
80<G<315\end{array}$ & $0.5<x<1$ & $\begin{array}{l}\text { Data has resulted in a considerable scatter. In } \\
\text { general, it agreed with the Lockhart and Martinelli } \\
\text { [34] equation for a straight tubes } \\
\qquad \phi_{l, t t}^{2}=1+\frac{C}{\chi_{t t}}+\frac{1}{\chi_{t t}^{2}} \\
\text { where } C \text { is a constant dependent on the gas and } \\
\text { liquid Reynolds numbers } \\
\chi_{t t}=\left(\frac{1-x}{x}\right)^{0.9}\left(\frac{\rho_{g}}{\rho_{l}}\right)^{0.5}\left(\frac{\mu_{l}}{\mu_{g}}\right)^{0.1}\end{array}$ \\
\hline $\begin{array}{c}\text { Kozeki } \\
(1970) \\
{[28]}\end{array}$ & $\begin{array}{c}21.7 \mathrm{~mm} \mathrm{OD} \\
628<D<682 \mathrm{~m} \\
\mathrm{~m}\end{array}$ & $\begin{array}{c}0.032<\delta<0.035 \\
0.5<P<2.1 \mathrm{MPa} \\
151<q<348 \\
161<G<486\end{array}$ & $0<x<1$ & $\begin{array}{l}\text { Pressure drop is greater than that for a straight tube } \\
\text { and it increases with vapour quality and mass flux.. }\end{array}$ \\
\hline
\end{tabular}




\begin{tabular}{|c|c|c|c|c|}
\hline & Vertical & & & $\begin{array}{l}\text { Numerical model based on the Martinelli and } \\
\text { Nelson prediction for two-phase flow in straight } \\
\text { tubes } \\
\qquad \begin{array}{r}\phi_{g, t t}{ }^{2}=0.895+\left(\chi_{t t}+0.076\right)^{0.875}+1.21 \\
* 10^{-0.334\left(\log \chi_{t t}+0.668\right)^{2}} \\
\text { where: } \\
\qquad \phi_{l t t}=\frac{\phi_{g, t t}}{\chi_{t t}^{0.875}}\end{array}\end{array}$ \\
\hline $\begin{array}{c}\text { Nariai et } \\
\text { al. }(1982) \\
{[10]}\end{array}$ & $\begin{array}{c}14.3 \& 20 \mathrm{~mm} \\
I D \\
D=595 \mathrm{~mm}\end{array}$ & $\begin{array}{c}0.024<\delta<0.034 \\
2<P<3.5 \mathrm{MPa} \\
0.7 \mathrm{E} 5<q<1.8 \mathrm{E} 5 \\
150<G<850\end{array}$ & $0.1<x<0.9$ & 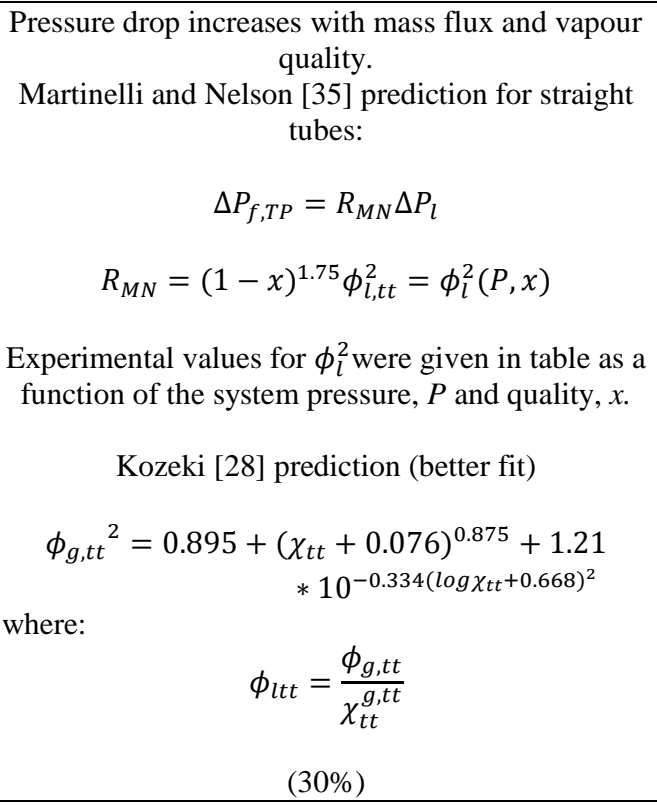 \\
\hline $\begin{array}{c}\text { Guo et al. } \\
(2001) \\
{[37]}\end{array}$ & $\begin{array}{l}10 \& 11 \mathrm{~mm} I D \\
D=132 \& 256 \\
\quad \mathrm{~mm}\end{array}$ & $\begin{array}{c}0.043<\delta<0.076 \\
3<P<3.5 \mathrm{MPa} \\
0<q<540 \\
150<G<1760\end{array}$ & $-0.01<x<1.2$ & $\begin{array}{l}\text { The coil orientation has a significant influence on } \\
\text { the frictional pressure drop. Pressure drop is also a } \\
\text { function of the system pressure and mass quality. } \\
\text { Based on Chen's [36] correlation for straight tubes: } \\
\qquad \phi_{l}{ }^{2}=\psi_{1} \psi\left[1+x\left(\frac{\rho_{l}}{\rho_{g}}-1\right)\right] \\
\text { where: } \\
\text { for } G \leq 1000 \quad x(1-x)\left(\frac{1000}{G}-1\right)\left(\frac{\rho_{l}}{\rho_{g}}\right) \\
\text { for } G>1000 \\
\qquad \psi=1+\frac{1+x\left(\frac{\rho_{l}}{\rho_{g}}-1\right)}{1+(1-x)\left(\frac{\rho_{l}}{\rho_{g}}-1\right)} \\
\qquad \psi_{1}=142.2\left(\frac{P}{P_{\text {crit }}}\right) \\
( \pm 12 \%)\end{array}$ \\
\hline \multicolumn{5}{|c|}{ Correlations for high system pressures based $(P>3.5 \mathrm{MPa})$} \\
\hline $\begin{array}{c}\text { Ruffell } \\
(1974) \\
{[39]}\end{array}$ & $\begin{array}{c}10.7<I D<18.6 \\
\mathrm{~mm}\end{array}$ & $\begin{array}{c}0.0054<\delta<0.16 \\
6<P<18 \mathrm{MPa} \\
41<q<731 \\
300 G<1800\end{array}$ & $0<x<1$ & $\begin{array}{l}\qquad \phi_{l}^{2}=(1+F) \frac{v_{m}}{v_{l}} \\
\text { where: } \\
F=\sin \left(\frac{1.16 G}{1000}\right)\left\{0.875-0.314 y-\frac{0.74 G}{1000}(0.152-\right. \\
\left.0.07 y)-x\left(\frac{0.155 G}{1000}+0.7-0.19 y\right)\right\}\{1-12(x- \\
0.3)(x-0.4)(x-0.5)(x-0.6)\}\end{array}$ \\
\hline
\end{tabular}




\begin{tabular}{|c|c|c|c|c|}
\hline & & & & $y=\frac{D}{100 d}$ \\
\hline $\begin{array}{l}\text { Unal et al. } \\
\text { (1981) } \\
\text { [40] }\end{array}$ & $\begin{array}{c}18 \mathrm{~mm} \mathrm{ID} \\
700 \& 1500 \mathrm{~mm} \\
=D \\
\text { Vertical }\end{array}$ & $\begin{array}{c}0.0054<\delta<0.022 \\
14.7<P<20.2 \mathrm{MPa} \\
41<q<731 \\
112<G<1829\end{array}$ & $0.08<x<1$ & $\begin{array}{l}\qquad \Delta P_{f, T P}=\frac{2\left(1+b_{1} b_{2}\right) f_{l} G^{2}}{d \rho_{l}} \\
\text { where: } \\
\qquad b_{1}=3850 x^{0.01} \mathrm{Pr}^{-1.515} \operatorname{Re}_{l}^{-0.758} \\
b_{2}=1+R e_{l}^{0.1}\left(3.67-3.04 P_{b}\right)^{\left(\left(-0.014 \delta^{-1}\right)-\left(2 \delta^{-1}\right)\right)} \\
\text { where; } \\
\qquad P_{b}=\frac{P}{P_{\text {crit }}} \\
f_{l}=0.076 R e^{-0.25}+0.00725 \delta^{0.5} \\
( \pm 20 \%)\end{array}$ \\
\hline $\begin{array}{l}\text { Chen and } \\
\text { Zhou } \\
(1981) \\
{[41]}\end{array}$ & $\begin{array}{c}18 \mathrm{~mm} \mathrm{ID} \\
235,446,907 \\
\mathrm{~mm}=D \\
\text { Vertical }\end{array}$ & $\begin{array}{c}0.02<\delta<0.076 \\
4.2<P<22 \mathrm{MPa} \\
400<G<2000\end{array}$ & $0<x<1$ & $\begin{array}{l}\qquad \Delta P_{f, T P}=\xi \Delta P_{s t} \\
\text { where: } \\
\xi=2.06 \delta^{0.05} R e_{T P}^{-0.025}\left[1+V F\left(\frac{\rho_{g}}{\rho_{l}}-1\right)\right]^{0.8}[1+ \\
\left.x\left(\frac{\rho_{l}}{\rho_{g}}-1\right)\right]^{1.8}\left[1+V F\left(\frac{\mu_{g}}{\mu_{l}}-1\right)\right]^{0.2}\end{array}$ \\
\hline $\begin{array}{l}\text { Santini et } \\
\text { al. }(2008) \\
\quad[38]\end{array}$ & $\begin{array}{c}12.53 \mathrm{~mm} \mathrm{ID} \\
D=1000 \mathrm{~mm} \\
\text { Vertical }\end{array}$ & $\begin{array}{c}\delta=0.019 \\
1.1<P<6.3 \mathrm{MPa} \\
50<q<200 \\
192<G<824\end{array}$ & $0<x<1$ & 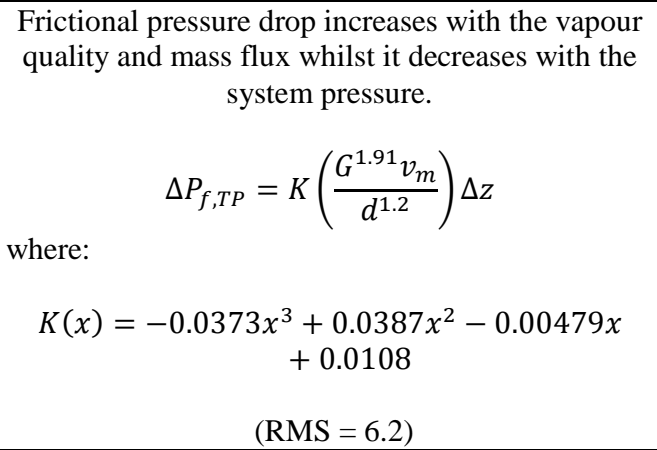 \\
\hline \multicolumn{5}{|c|}{ Correlations for large tube diameters $(d \geq 12 \mathrm{~mm})$} \\
\hline $\begin{array}{l}\text { Guo et al. } \\
\text { (1994) } \\
{[42]}\end{array}$ & $\begin{array}{c}20 \mathrm{~mm} I D \\
240,480,960 \\
\mathrm{~mm}=D \\
\text { Horizontal }\end{array}$ & $\begin{array}{c}0.021<\delta<0.083 \\
1.5<P<3 \mathrm{MPa} \\
150<G<1400\end{array}$ & $0<x<0.8$ & $\emptyset_{l}^{2}=1+\left(4.25-2.55 x^{1.5}\right) G^{0.34}$ \\
\hline \multicolumn{5}{|c|}{ Correlations for small tube and helix diameters $(d<12 \mathrm{~mm})$} \\
\hline $\begin{array}{c}\text { Kubair } \\
(1986) \\
{[43]}\end{array}$ & $\begin{array}{l}6.4 \& 6.5 \mathrm{~mm} \\
\qquad I D \\
110<D<177 \\
\text { Laminar \& } \\
\text { Turbulent } \\
\text { Vertical }\end{array}$ & $\begin{array}{c}0.037<\delta<0.056 \\
8<P<16 \mathrm{kPa} \\
6<q<80 \\
0.0028<\dot{m}<0.016 \\
1300<\operatorname{Re}<5200\end{array}$ & $0.2<x<0.8$ & $\begin{array}{l}\text { Frictional pressure drop is larger than that for } \\
\text { straight tubes. } \\
\text { No correlation provided. }\end{array}$ \\
\hline $\begin{array}{c}\text { Bi et al. } \\
(1994) \\
{[32]}\end{array}$ & $\begin{array}{c}10 \& 12 \mathrm{~mm} \mathrm{ID} \\
D=115 \mathrm{~mm} \\
\text { Horizontal\& } \\
\text { Vertical }\end{array}$ & $\begin{array}{c}0.087<\delta<0.104 \\
4<P<14 \mathrm{MPa} \\
0<q<750 \\
400<G<2000\end{array}$ & $0<x<1$ & $\begin{array}{l}\text { Coil orientation has no significant effect on the two- } \\
\text { phase frictional pressure drop. The two-phase } \\
\text { frictional pressure drop was not influenced by the } \\
\text { conditions of the thermodynamic system i.e. } \\
\text { adiabatic or electrically heated tubes. } \\
\qquad \phi_{l}^{2}=1+\left[\frac{\rho_{l}}{\rho_{g}}-1\right]\left[C+x^{2}\right] \\
\text { where: }\end{array}$ \\
\hline
\end{tabular}




\begin{tabular}{|c|c|c|c|c|}
\hline & & & & $\begin{array}{c}C=0.14691 x^{1.3297}(1-x)^{0.59884} \delta^{-1.2864} \\
( \pm 15 \%)\end{array}$ \\
\hline $\begin{array}{c}\text { Ju et al. } \\
\text { (2001) } \\
\text { [44] }\end{array}$ & $\begin{array}{c}18 \mathrm{~mm} O D \\
D=112 \mathrm{~mm} \\
\text { Turbulent }\end{array}$ & $\begin{array}{c}\delta=0.161 \\
P=3 \mathrm{MPa} \\
2500<R e \\
<23000\end{array}$ & $0<x<1$ & $\begin{array}{l}\qquad \Delta P_{f, T P}=f\left(\frac{L}{d}\right)\left(\frac{\rho V^{2}}{2}\right)\left[1+x\left(\frac{\rho^{\prime}}{\left(\rho^{\prime \prime}-1\right)}\right)\right] \psi \\
\text { where: } \\
\qquad \psi=\left(1.29+A_{n} x^{n}\right)\left[1+x\left(\left(\frac{\mu^{\prime \prime}}{\mu^{\prime}}\right)^{0.25}-1\right)\right] \\
\qquad A_{l}=2.19, A_{2}=-3.61, A_{3}=7.35, A_{4}=-5.93\end{array}$ \\
\hline $\begin{array}{l}\text { Zhao et al. } \\
\text { (2003) } \\
\text { [27] }\end{array}$ & $\begin{array}{c}9 \mathrm{~mm} I D \\
D=292 \mathrm{~mm} \\
\text { Laminar } \\
\text { Horizontal }\end{array}$ & $\begin{array}{c}\delta=0.031 \\
0.5<P<3.5 \mathrm{MPa} \\
0<q<900 \\
236<G<943 \\
10000<\operatorname{Re} \\
<80000\end{array}$ & $0.1<x<0.2$ & 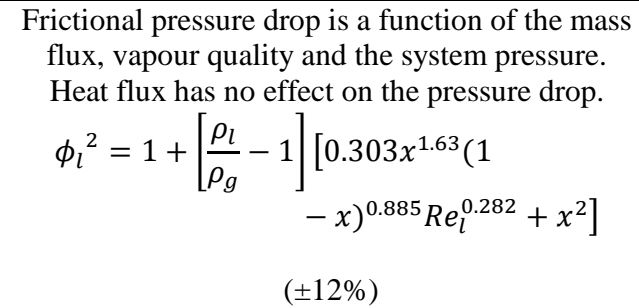 \\
\hline $\begin{array}{l}\text { Cioncolini } \\
\text { et al. } \\
(2008) \\
{[26]}\end{array}$ & $\begin{array}{c}4.03 \& 4.98 \mathrm{~mm} \\
\qquad I D \\
130<D<376 \\
\text { Turbulent } \\
\text { Vertical } \\
\text { Saturated flow } \\
\text { boiling }\end{array}$ & $\begin{array}{c}0.011<\delta<0.038 \\
120<P<660 \mathrm{kPa} \\
50<q<440 \\
290<G<690 \\
10000<R e \\
<60000 \\
2<F r<14\end{array}$ & $0<x<0.9$ & $\begin{array}{l}\text { Minimal effect of the coil curvature on the } \\
\text { frictional pressure drop. } \\
\text { Lockhart and Martinelli correlation for straight } \\
\text { tubes corrected for heating effects [45]: } \\
\phi_{l}^{2}=\left[1+\frac{C}{\chi_{t t}}+\frac{1}{\chi_{t t}^{2}}\right]\left[1+0.0044\left(\frac{q}{G}\right)^{0.7}\right] \\
(16.7 \%) \\
\text { Zhao et al. [27] } \\
\phi_{l}^{2}=1+\left[\frac{\rho_{l}}{\rho_{g}}-1\right]\left[0.303 x^{1.63}(1\right. \\
\left.-x)^{0.885} R_{l}^{0.282}+x^{2}\right] \\
(16.3 \%)\end{array}$ \\
\hline
\end{tabular}

Table 1: Review of the experimental studies on the flow boiling frictional pressure drop characteristics of steam-water in helically coiled tubes

\section{2. $R-134 a$}

The pressure drop characteristics and relevant correlations for flow boiling and condensation of R-134a in helically coiled tube heat exchangers are summarised in Table 2. In contrast to the conclusions made by a number of investigations on steam and water flow boiling, the curvature ratio appears to have some impact on the resultant frictional pressure drop for R134a flow in non-miniature helically coiled tubes. The pertinent investigations have also concluded that the frictional pressure drop increases with higher vapour qualities and refrigerant mass fluxes, whilst the tube orientation has no significant impact on the pressure drop. The total two-phase pressure drop for the flow boiling of R-134a in micro-finned helically coiled tubes is given in Eq. (6) [46] whilst the two-phase frictional pressure drop was calculated through the use of the pressure drop multiplier as in Eq. (3).

$\Delta P_{\text {total }, T P}=\Delta P_{f, T P}+\Delta P_{\text {grav }}+\Delta P_{\text {mom }, T P}$

where:

$\Delta P_{\text {grav }}=g \rho_{l} \tan \beta(1-V F)$ 
Aria et al. [47]:

Cui et al. [46]

$V F=\frac{1}{1+0.49 \chi_{t t}^{0.8036}}$

Elsayed et al. [48]

$V F=\frac{1}{\left[1+0.79\left(\frac{(1-x)}{x}\right)^{0.78}\left(\frac{\rho_{v}}{\rho_{l}}\right)^{0.58}\right]}$

Wongwises and Polsongkram [49]

$V F=\frac{1}{1+S\left(\frac{1-x}{x}\right) \frac{\rho_{v}}{\rho_{l}}}$

Laohalertdecha and Wongwises [50]

$V F=\left[1+\frac{(1-x)}{x}\left(\frac{\rho_{v}}{\rho_{l}}\right)^{2 / 3}\right]^{-1}$

The numerical models for the R-134a refrigerant frictional pressure drop in vertical helically coiled tubes as reported in the pertinent studies are a function of the Lockhart and Martinelli parameter, whilst the sole correlation for horizontal tubes is based on a numerical model by Kim et al. [51] for R-22 flow in coiled tubes. There is a general agreement that the higher mass fluxes and the vapour qualities increase the frictional pressure drop. These results are attributed to the higher vapour velocities which increase the shear stress at the interface of the vapour and the liquid. Furthermore, higher vapour qualities result in increased magnitudes of secondary flow which will result in higher degrees of entrainment and droplet redeposition, thus yielding greater flow turbulences [49]. Moreover, Lin and Ebadian [52] reported that when compared to the flow in the inner tube, the effects of the mass flux on the pressure drop were more significant in the annular section of the coil. These findings were attributed to the larger velocity and turbulence fluctuations of the refrigerant flowing in the annular section.

The effects of the coil geometry on the two-phase refrigerant frictional pressure drop were investigated by Scott Downing and Kojasoy [53] and Elsayed et al. [48]. For miniature diameter tubes, Downing and Kojasoy reported that when compared to single-phase flow, the curvature effects had a minimal impact on the frictional pressure drop. However, for small diameter tubes, Elsayed et al. reported that the frictional pressure drop is mainly a function of the tube diameter, with the pressure drop increasing with smaller tube diameters. The effect of the coil diameter was reported to be less significant. Elsayed et al. focused their study on the heat transfer characteristics and hence failed to provide a comprehensive analysis of their reported results.

When investigating the frictional pressure drop as a function of the heat flux, Wongwises and Polsongkram [54] reported that the heat flux had a minimal effect on the condensation frictional pressure drop. However, the evaporation frictional pressure drop was 
reported to be a strong function of the heat flux [49]. This was attributed to the increase in the number of active nucleation sites on the tube wall which yielded higher bubble generation rates. The latter agitated the liquid film thus increasing the turbulence. Furthermore, the breaking of the bubbles at the liquid film surface induced the entrainment and redeposition of droplets which increased the shear stress. Kang et al. [11] and Wongwises and Polsongkram [49, 54] reported a decrease in the frictional pressure drop with higher wall temperatures. These results were attributed to the lower refrigerant viscosity and specific volume, which in turn resulted in a lower vapour velocity and shear stress between the vapour and liquid interface.

The sole study that investigated the frictional pressure drop of R-134a as a function of the coil orientation was reported by Lin and Ebadian [52] who concluded that the coil orientation resulted in an insignificant impact on the frictional pressure drop. The applications of micro-finned or corrugated helically coiled tubes were investigated by Cui et al. [46] and Laohalertdecha and Wongwises [50]. Both investigations reported correlations for the pressure drop multiplier based on the Lockhart and Martinelli numerical model for straight tubes. Moreover, both authors reported a significant increase in the frictional pressure drop (up to $70 \%$ ) over that of a smooth tube. Laohalertdecha and Wongwises attributed these results to the increased drag forces, the flow blockage due to the reduction in the tube cross-sectional area, the turbulence augmentation and the enhanced rotational flow reduction. The impact of the vapour quality and mass flux on the frictional pressure drop was similar to that reported for smooth tubes.

\begin{tabular}{|c|c|c|c|c|}
\hline Authors & $\begin{array}{l}\text { Helical coil design } \\
\text { parameters }\end{array}$ & $\begin{array}{c}\text { Principal } \\
\text { experimental } \\
\text { parameters }\end{array}$ & Quality & $\begin{array}{c}\text { Main conclusions, proposed correlation and } \\
\text { mean error }\end{array}$ \\
\hline \multicolumn{5}{|c|}{ Miniature $\left(d_{i t}<1 \mathrm{~mm}\right)$} \\
\hline $\begin{array}{c}\text { Scott } \\
\text { Downin } \\
\text { g and } \\
\text { Kojasoy } \\
(2002) \\
{[53]}\end{array}$ & $\begin{array}{l}234<I D<881 \mu \mathrm{m} \\
2.80<D<7.94 \mathrm{~mm}\end{array}$ & $\begin{array}{c}0.075<\delta_{i t}<0.3 \\
0.62<P<1.4 \mathrm{M} \\
\mathrm{Pa} \\
0<q<25 \\
750<G<6330 \\
500<\operatorname{Re}<8000\end{array}$ & $\begin{array}{c}\quad 0<x<0.9 \\
\text { Evaporation }\end{array}$ & 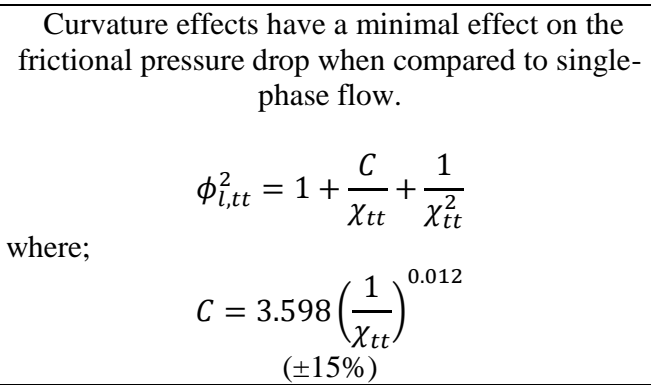 \\
\hline \multicolumn{5}{|c|}{ Vertical orientation \& Smooth tubes } \\
\hline $\begin{array}{l}\text { Kang et } \\
\text { al. } \\
(2000) \\
{[11]}\end{array}$ & $\begin{array}{l}\text { Tube-in-tube } \\
12.7 \mathrm{~mm} I D_{i t} \\
21.2 \mathrm{~mm} I D_{o t} \\
D=177.8 \mathrm{~mm} \\
\text { Laminar \& } \\
\text { Turbulent }\end{array}$ & $\begin{array}{c}\delta_{i t}=0.075 \\
100<G<400 \\
T=33^{0} \mathrm{C} \\
1500<\operatorname{Re}<900 \\
0\end{array}$ & $\begin{array}{l}\quad 0<x<1 \\
\text { Condensatio } \\
\mathrm{n}\end{array}$ & $\begin{array}{l}\text { Very slow increase in the pressure drop with an } \\
\text { increase in the mass flux. } \\
\text { Pressure drop is a function of the cooling wall } \\
\text { temperature, with a decrease in the pressure drop } \\
\text { with an increase in the wall temperature. } \\
\text { For } T_{\text {wall }}=12^{\circ} \mathrm{C}, \Delta P_{T P}=14.2 m_{\text {ref }}^{0.093} \\
\text { For } T_{\text {wall }}=22^{\circ} \mathrm{C}, \Delta P_{T P}=4.2 m_{\text {ref }}^{0.26} \\
(-37.3 \% \text { to } 35.7 \%)\end{array}$ \\
\hline $\begin{array}{l}\text { Han et } \\
\text { al. } \\
(2005) \\
{[55]}\end{array}$ & $\begin{array}{l}\text { Tube-in-tube } \\
9.4 \mathrm{~mm} I D_{i t} \\
12.7 \mathrm{~mm} O D_{i t} \\
21.2 \mathrm{~mm} I D_{o t} \\
\\
D=177.8 \mathrm{~mm}\end{array}$ & $\begin{array}{c}\delta_{i t}=0.053 \\
100<G<420 \\
T_{s a t}=35,40,46^{0} \\
\mathrm{C} \\
1500<\operatorname{Re}<900 \\
0\end{array}$ & $\begin{array}{l}\quad 0<x<1 \\
\text { Condensatio } \\
\mathrm{n}\end{array}$ & $\begin{array}{l}\text { Pressure drop increases with refrigerant mass flux. } \\
\text { Frictional pressure drop is higher than that in a } \\
\text { straight tube, whilst the effect of the mass flux on } \\
\text { the pressure drop is more significant in straight } \\
\text { tubes. } \\
\text { No correlation provided }\end{array}$ \\
\hline $\begin{array}{l}\text { Wongwi } \\
\text { ses and } \\
\text { Polsong }\end{array}$ & $\begin{array}{l}\text { Tube-in-tube } \\
7.2 \mathrm{~mm} I D_{i t} \\
9.52 \mathrm{~mm} O D_{i t} \\
21.2 \mathrm{~mm} I D_{o t}\end{array}$ & $\begin{array}{c}\delta_{i t}=0.025 \\
5<q<10 \\
400<G<800\end{array}$ & $\begin{array}{c}0.0<x<1 \\
\text { Evaporation }\end{array}$ & $\begin{array}{l}\text { Increase in the frictional pressure drop with } \\
\text { increasing quality, mass flux and heat flux. } \\
\text { Marginal decrease with increasing saturation } \\
\text { temperature. }\end{array}$ \\
\hline
\end{tabular}




\begin{tabular}{|c|c|c|c|c|}
\hline $\begin{array}{c}\text { kram } \\
(2006 \mathrm{a}) \\
{[49]}\end{array}$ & $\begin{array}{c}23.2 \mathrm{~mm} O D_{o t} \\
D=305 \mathrm{~mm}\end{array}$ & $10<T_{\text {sat }}<20^{\circ} \mathrm{C}$ & & $\begin{array}{c}\qquad \phi_{l}^{2}=1+\frac{13.37}{\chi_{t t}^{1.492}} \\
\text { Used Ito's [6] correlation for the single-phase } \\
\text { friction factor } \\
( \pm 20 \%)\end{array}$ \\
\hline $\begin{array}{c}\text { Wongwi } \\
\text { ses and } \\
\text { Polsong } \\
\text { kram } \\
(2006 \mathrm{~b}) \\
{[54]}\end{array}$ & $\begin{array}{c}\text { Tube-in-tube } \\
8.3 \mathrm{~mm} I D_{i t} \\
9.52 \mathrm{~mm} O D_{i t} \\
21.2 \mathrm{~mm} I D_{o t} \\
23.2 \mathrm{~mm} O D_{o t} \\
D=305 \mathrm{~mm}\end{array}$ & $\begin{array}{c}\delta_{i t}=0.025 \\
5<q<10 \\
400<G<800 \\
40<T_{\text {sat }}<50^{\circ} \mathrm{C}\end{array}$ & $\begin{array}{l}0.01<x<1 \\
\text { Condensatio } \\
\mathrm{n}\end{array}$ & $\begin{array}{l}\text { Frictional pressure drop increases with average } \\
\text { vapour quality and mass flux and decreases with } \\
\text { increasing saturation temperature of condensation. } \\
\text { Heat flux has a minimal effect on the pressure } \\
\text { drop. } \\
\qquad \phi_{l}^{2}=1+\frac{5.569}{\chi_{t t}^{1.492}}+\frac{1}{\chi_{t t}^{2}} \\
\text { Used Ito's [6] correlation for the single-phase } \\
\text { friction factor } \\
( \pm 20 \%)\end{array}$ \\
\hline $\begin{array}{c}\text { El-Sayed } \\
\text { Mossad } \\
\text { et al. } \\
(2009) \\
{[56]}\end{array}$ & $\begin{array}{c}\text { Tube-in-tube } \\
7.39 \mathrm{~mm} I D_{i t} \\
9.54 \mathrm{~mm} O D_{i t} \\
16.92 \mathrm{~mm} I D_{o t} \\
19.05 \mathrm{~mm} O D_{o t} \\
D=216 \mathrm{~mm}\end{array}$ & $\begin{array}{c}\delta_{i t}=0.03 \\
810<P<820 \mathrm{kP} \\
\mathrm{a} \\
2.5<q<12 \\
95<G<710 \\
1000<\operatorname{Re}<140 \\
00\end{array}$ & $\begin{array}{c}0.0<x<1 \\
\text { Condensatio } \\
\mathrm{n}\end{array}$ & $\begin{array}{l}\text { Increase in the frictional pressure drop with the } \\
\text { refrigerant mass flux. } \\
\text { Pressure drop is significantly higher than in a } \\
\text { straight tube. } \\
\text { Used Han et al.'s [55] correlation }\end{array}$ \\
\hline $\begin{array}{l}\text { Aria et } \\
\text { al. } \\
(2012) \\
{[47]}\end{array}$ & $\begin{array}{l}\text { Tube-in-tube } \\
8.9 \mathrm{~mm} I D_{i t} 9.52 \mathrm{~mm} \\
O D_{i t} 29 \mathrm{~mm} I D_{o t} \\
D=305 \mathrm{~mm}\end{array}$ & $\begin{array}{c}\delta_{i t}=0.031 \\
112<G<152\end{array}$ & $\begin{array}{l}0.1<x<0.8 \\
\text { Evaporation }\end{array}$ & $\begin{array}{l}\text { Pressure drop increases with higher inlet vapour } \\
\text { quality and refrigerant mass flow rate. } \\
\text { 150-220\% higher than pressure drop in straight } \\
\text { tubes. } \\
\text { Used Wongwises and Polsongkram's [49] } \\
\text { correlation for helical tubes } \\
(-73 \% \text { to }+39 \%)\end{array}$ \\
\hline \multicolumn{5}{|c|}{ Micro-finned or corrugated tube } \\
\hline $\begin{array}{l}\text { Cui et al. } \\
(2008) \\
{[46]}\end{array}$ & $\begin{array}{c}\text { Micro-finned } \\
11.2 \mathrm{~mm} \mathrm{ID} \\
12.7 \mathrm{~mm} O D \\
D=185 \mathrm{~mm} \\
\\
\text { Vertical }\end{array}$ & $\begin{array}{c}\delta=0.061 \\
0.5<P<0.58 \mathrm{M} \\
\mathrm{Pa} \\
2.0<q<21.8 \\
65<G<315\end{array}$ & $\begin{array}{l}0.05<x<0.92 \\
\text { Evaporation }\end{array}$ & $\begin{array}{l}\text { Two-phase pressure drop is greater than that in a } \\
\text { straight pipe. Micro-fins also increase the pressure } \\
\text { drop as does increasing mass flux and vapour exit } \\
\text { quality. } \\
\text { For Stratified flow: } \\
\qquad \phi_{l}^{2}=1+\frac{48.2}{\chi_{t t}}+\frac{1}{\chi_{t t}^{2}} \\
\text { For Annular flow: } \\
\qquad \phi_{l}^{2}=1+\frac{59.8}{\chi_{t t}}+\frac{3.5}{\chi_{t t}^{2}} \\
\text { Ito's [6] correlation for the single-phase friction } \\
\text { factor was used } \\
( \pm 20 \%)\end{array}$ \\
\hline $\begin{array}{l}\text { Laohaler } \\
\text { tdecha } \\
\text { and } \\
\text { Wongwi } \\
\text { ses } \\
(2010) \\
{[50]}\end{array}$ & $\begin{array}{c}\text { Corrugated } \\
I D_{i t}=8.7 \mathrm{~mm} \\
O D_{i t}=9.52 \mathrm{~mm} \\
I D_{o t}=21.2 \mathrm{~mm} \\
E=1.5 \mathrm{~mm} \\
\text { Horizontal }\end{array}$ & $\begin{array}{c}5<q<10 \\
200<G<700 \\
T_{\text {sat }}=40,45,50^{0} \\
\text { C }\end{array}$ & $\begin{array}{l}0.01<x<0.9 \\
\text { Condensatio } \\
\mathrm{n}\end{array}$ & $\begin{array}{l}\text { Frictional pressure drop increases with refrigerant } \\
\text { mass flux and quality. } \\
70 \% \text { increase in the frictional pressure drop over } \\
\text { that of smooth tubes }\end{array}$ \\
\hline
\end{tabular}




\begin{tabular}{|c|c|c|c|c|}
\hline & & & & $\begin{array}{c}\phi_{l, t t}^{2}=1+\frac{10}{\chi_{t t}}+\frac{1}{\chi_{t t}^{2}} \\
( \pm 30 \%)\end{array}$ \\
\hline \multicolumn{5}{|c|}{ Horizontal orientation \& Smooth tubes } \\
\hline $\begin{array}{l}\text { Elsayed } \\
\text { et al. } \\
(2012) \\
{[48]}\end{array}$ & $\begin{array}{c}1.1<I D<2.8 \mathrm{~mm} \\
1.47<O D<4 \mathrm{~mm} \\
30<D<60 \mathrm{~mm}\end{array}$ & $\begin{array}{c}0.037<\delta<0.04 \\
7 \\
0.35<P<0.6 \mathrm{M} \\
\mathrm{Pa} \\
2.5<q<12 \\
100<G<450\end{array}$ & $\begin{array}{l}0.2<x<0.9 \\
\text { Evaporation }\end{array}$ & $\begin{array}{l}\text { Frictional pressure drop is a strong function of the } \\
\text { inner tube diameter. The coil diameter has a } \\
\text { marginal effect on the pressure drop. } \\
\text { Kim et al.'s [51] correlation for R-22: } \\
\qquad \begin{array}{c}\Delta P_{f, T P}=2 \frac{f_{T P} G_{r e f}^{2}}{\rho_{l} d_{i t}}\left[1+x \frac{\left(\frac{1}{\rho_{v}}-\frac{1}{\rho_{l}}\right)}{\frac{1}{\rho_{v}}}\right] \\
\text { where: } \\
\qquad f_{T P}=0.079\left(\frac{G_{r e f} d_{i t}}{\mu_{T P}}\right)^{-0.25} \\
\mu_{T P}=\rho_{T P}\left[\frac{\chi \mu_{v}}{\rho_{v}}+\frac{(1-\chi) \mu_{l}}{\rho_{l}}\right] \\
\rho_{T P}=\rho_{v} V F+\rho_{l}(1-V F)\end{array}\end{array}$ \\
\hline \multicolumn{5}{|c|}{ Various orientations and smooth tube } \\
\hline $\begin{array}{c}\text { Lin and } \\
\text { Ebadian } \\
(2007) \\
{[52]}\end{array}$ & $\begin{array}{c}\text { Tube-in-tube } \\
9.4 \mathrm{~mm} I D_{i t} \\
12.7 \mathrm{~mm} O D_{i t} \\
21.2 \mathrm{~mm} I D_{o t} \\
D=177.8 \mathrm{~mm} \\
\text { Horizontal } / 45^{\circ} / \text { Verti } \\
\text { cal }\end{array}$ & $\begin{array}{c}\delta_{i t}=0.053 \\
60<\operatorname{Re}_{\text {ref }}<200 \\
3600<\operatorname{Re}_{w t}<22 \\
000 \\
30<T_{\text {ref }}<35 \\
16<T_{w t}<24\end{array}$ & $\begin{array}{c}\text { Condensatio } \\
n\end{array}$ & $\begin{array}{l}\text { The effects of the tube orientation on the pressure } \\
\text { drop were not significant whilst the effects of the } \\
\text { refrigerant mass flow rate on the pressure drop } \\
\text { were more significant in the annular section of the } \\
\text { pipe when compared to the inner tube. } \\
\qquad \phi_{l}^{2}=1-\frac{1.271}{\chi_{t t}^{1.492}}+\frac{1}{\chi_{t t}^{2}} \\
( \pm 6 \%)\end{array}$ \\
\hline
\end{tabular}

Table 2: Review of experimental studies on the flow boiling/condensing frictional pressure drop characteristics of $\mathbf{R}-134 \mathrm{a}$ in helically coiled tubes

\section{Gas-Water}

In contrast to the paucity of studies on the gas-water two-phase flow heat transfer characteristics in helically coiled tubes [57], the open literature presents numerous studies on the two-phase gas-water pressure drop characteristics. Table 3 summarises the experimental studies and correlations for the frictional pressure drop with gas and water two-phase flow as presented in the pertinent literature. The majority of studies reviewed in this section have demonstrated a reasonable agreement with the original and modified Lockhart and Martinelli correlations. Some investigators have also reported the helix angle and the curvature ratio to have some impact on the frictional pressure drop whilst other investigators reported the frictional pressure drop to be independent of the latter design parameters. The effects of the air volumetric void fraction remain indeterminate due to conflicting results. As in the case of steam-water flow, the total two-phase pressure drop with air-water systems is calculated through Eq. (2) whilst the two-phase frictional pressure drop is calculated through the application of the pressure drop multiplier as in Eq. (3).

Most studies on the two-phase air-water flow in helically coiled tubes were developed for vertically orientated tubes. The earliest study was reported by Rippel at al. [58] who investigated annular, bubbly, slug, and stratified flows. In agreement with some studies reported for steam-water, they reported that the Lockhart and Martinelli correlation for 
horizontal straight tubes predicted their data with reasonable accuracy. These results were attributed to the fact that the Lockhart and Martinelli parameters are essentially ratios, while the geometry of the tube does not impact on the ratio of the two-phase to single-phase pressure drop given in Eq. (3). However, they also reported that the latter methodology also results in a number of limitations, principally due to the fact that some pertinent factors that affect twophase flows are neglected. In view of this, Rippel et al. presented three empirical correlations for the calculation of the two-phase flow pressure drop for annular, bubbly and stratified flows. These correlations are based on the two-phase drag coefficient. Banerjee et al. [59] reported similar results with the Lockhart and Martinelli correlation and presented modified equations for the gas and liquid pressure drop multipliers, and the Lockhart and Martinelli parameter. Banerjee were the first investigators to report that the helix angle did not have a significant impact on the frictional pressure drop. Agakawa et al. [4] also reported a good agreement with the Lockhart and Martinelli correlation whilst the frictional pressure drop was reported to be independent of the coil curvature. They also presented two key empirical correlations to calculate the ratios of the two-phase frictional pressure drop in the coil to those in a straight tube and coil with liquid flow only. Xin et al. [8] presented a further development of the Lockhart and Martinelli correlation whereby they included the effects of the three main forces affecting the pressure drop these being: the inertia, liquid gravity and centrifugal forces. In fact, they reported that the helix angle, coil diameter and pipe diameter had some effect on the frictional pressure drop. Awwad et al. [20,60] investigated the two-phase frictional pressure drop in horizontal helically coiled tubes. Their conclusions and correlations are similar to those presented by Xin et al. [8] for vertical tubes. Therefore, whilst being based on the original Lockhart and Martinelli model, their correlations for horizontal coils included the effects of the three principal forces affecting two-phase flow in coiled tubes.

Xin et al. [61] investigated the two-phase flow frictional pressure drop in annular helicoidal pipes. As done in their earlier study [8] on vertical coils, they presented a correlation for the calculation of the pressure drop multiplier which is a function of the Lockhart and Martinelli parameter, as well as the Froude number. However, for the case of the annular tubes, the latter is also a function of the inner and outer tube diameters. Vashisth and Nigam [62] were the sole authors to investigate the frictional pressure drop in a coiled flow inverter. The pressure drop was reported to be significantly higher than that for a straight helix. This result was attributed to the higher recirculation rates and the complete flow inversion as a result of the sudden shift in the flow direction. Vashisth and Nigam also reported that the Lockhart and Martinelli correlation, both in its original and modified form, predicted their data for a very limited range of flow rates. Therefore, they presented their own correlation for the two-phase friction factor in a coiled flow inverter which is a strong function of the number of bends and the curvature ratio. The latter was included due to their conclusions that smaller coil diameters resulted in higher intensity secondary flows which consequently increased the two-phase frictional pressure drop.

Chen and Guo [63] investigated the three phase oil-air-water flow in helically coiled tubes. The frictional pressure drop was reported to be independent of the coil diameter whilst, due to increased mixture viscosities, higher oil fractions resulted in higher pressure drops. A correlation which is essentially a modified Chisholm correlation for straight tubes was also presented. Chisholm's correlation was also used to correlate the data for sulphur hexafluoridewater flow in helically coiled tubes [64]. The sole study in the pertinent literature that investigated the gas-non-Newtonian pressure drop in helically coiled tubes was reported by Biswas and Das [65]. They reported a large deviation with the Lockhart and Martinelli correlation which was attributed to the non-Newtonian fluid properties. Therefore, they presented an empirical correlation for the calculation of the friction faction factor which is a function of the fluid and gas Reynolds number, the curvature ratio and fluid properties. In 
agreement to pertinent conclusions made for gas-water flow [20,59], the impact of the helix angle on the frictional pressure drop was also found to be negligible.

A recent study reported by Saffari et al. [17] investigated the frictional drag reduction through the use of two-phase bubbly flow in vertical helically coiled tubes. This study is based on earlier initiatives developed for straight tubes whereby two-phase bubbly flow resulted in a drag reduction over the corresponding single-phase flow [66, 67]. For turbulent flow with an air volumetric void fraction of 0.09 , Saffari et al. reported a maximum drag reduction of $25 \%$ over that of single-phase flow, ceteris paribus (Fig. 4). The latter reduction was at its highest at the lower end of the turbulent flow Reynolds numbers. Saffari et al. attributed these results to the impact of the centrifugal force on the lighter phase, this being air, whereby due to their lighter density, bubbles accumulate on the tube inner wall in the flow boundary layer. At lower Reynolds numbers these bubbles are widely spread on the tube wall and consequently result in a significant reduction of the turbulent Reynolds stresses. Such results are in contrast to the findings reported in this section where all investigators reported frictional pressure drop multipliers in excess of 1.

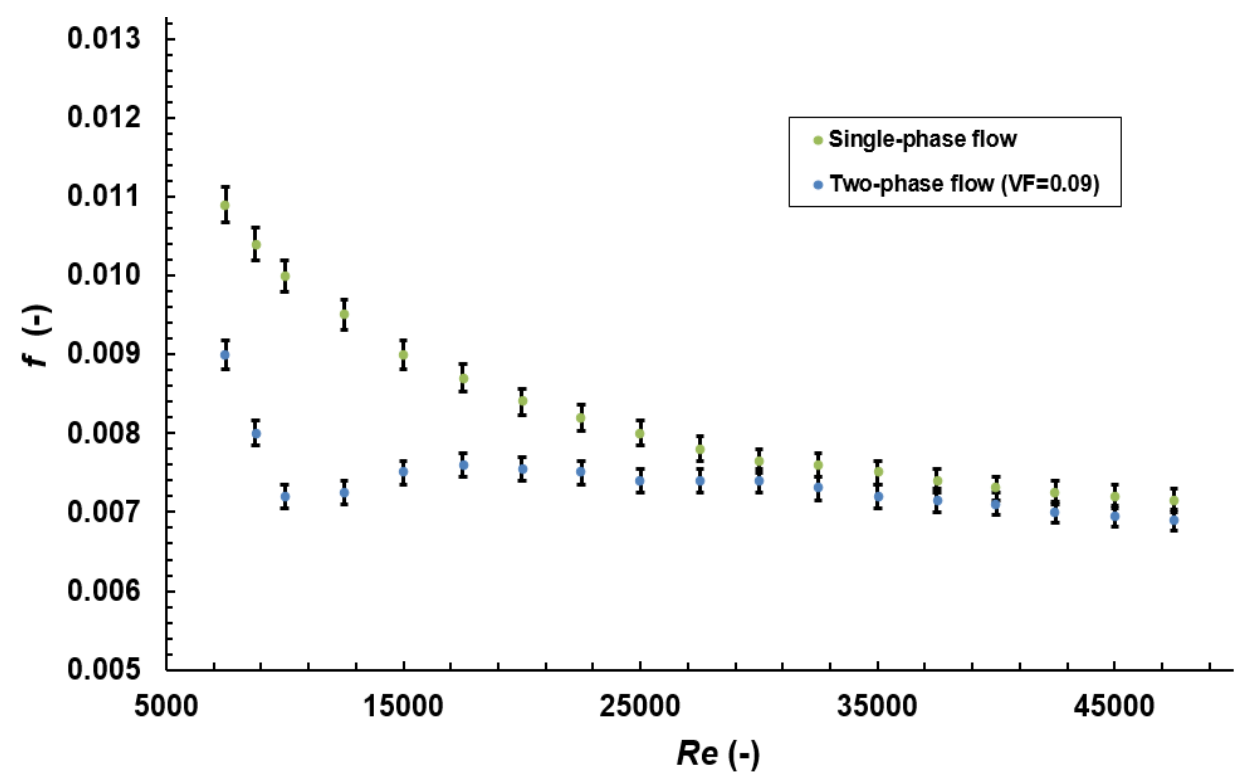

Figure 4: Comparison of the friction factor for single-phase and two-phase flow in helically coiled tubes at a volumetric void fraction of 0.09 (Saffari et al. [17], Fig. 4)

\begin{tabular}{|c|c|c|c|}
\hline Authors & $\begin{array}{l}\text { Helical coil design } \\
\text { parameters }\end{array}$ & $\begin{array}{c}\text { Principal } \\
\text { experimental } \\
\text { parameters }\end{array}$ & Main conclusions, proposed correlation and mean error \\
\hline \multicolumn{4}{|c|}{ Vertical orientation - Air-Water } \\
\hline $\begin{array}{c}\text { Rippel et } \\
\text { al. } \\
(1966) \\
{[58]}\end{array}$ & $\begin{array}{l}d=6.35 \mathrm{~mm} \\
D=203 \mathrm{~mm}\end{array}$ & $\begin{array}{c}\delta=0.031 \\
100<\operatorname{Re}<15000 \\
\text { Bubbly\&Slug/An } \\
\text { nular/Stratified }\end{array}$ & $\begin{array}{l}\text { Data fitted the Lockhart-Martinelli parameter. Developed } \\
\text { correlations based on the two-phase drag coefficient. } \\
\text { Annular Flow: } \\
\qquad\left(\frac{\Delta P}{\Delta L}\right)_{f, T P}=\left(\frac{\Delta P}{\Delta L}\right)_{g}+4.44 \varepsilon^{0.86}\left(\frac{\rho_{g} U^{2}}{g d}\right) \\
\text { Bubble and Slug Flow: } \\
\qquad\left(\frac{\Delta P}{\Delta L}\right)_{f, T P}=\left(\frac{\Delta P}{\Delta L}\right)_{g}+31.3 \varepsilon^{1.25}\left(\frac{\rho_{g} U^{2}}{g d}\right) \\
\text { Stratified Flow: } \\
\qquad\left(\frac{\Delta P}{\Delta L}\right)_{f, T P}=\left(\frac{\Delta P}{\Delta L}\right)_{g}+3.2 \varepsilon^{0.875}\left(\frac{\rho_{g} U^{2}}{g d}\right)\end{array}$ \\
\hline
\end{tabular}




\begin{tabular}{|c|c|c|c|}
\hline $\begin{array}{l}\text { Banerjee } \\
\text { et al. } \\
(1969) \\
{[59]}\end{array}$ & $\begin{array}{c}15.34<d<54.8 \mathrm{~mm} \\
152<D<610 \mathrm{~mm}\end{array}$ & $\begin{array}{l}0.108<\delta<0.090 \\
500<\operatorname{Re}<40000\end{array}$ & $\begin{array}{l}\text { Helix angle had no significant effect on the frictional pressure } \\
\text { drop. Data correlated well with the Lockhart and Martinelli } \\
\text { correlation using the modified } \emptyset_{l}, \emptyset_{g} \text { and } \chi_{t t} \text {; } \\
\qquad \emptyset_{l}^{2}=S F^{n-2}\left(\frac{d}{H D_{l}}\right)^{5-n} \\
\qquad \begin{array}{c}\emptyset_{g}^{2}=S F^{m-2}\left(\frac{d}{H D_{g}}\right)^{5-m} \\
\chi_{t t}^{2}=\frac{\left(\frac{\Delta P}{\Delta z}\right)_{l}}{\left(\frac{\Delta P}{\Delta z}\right)_{g}} \\
( \pm 30 \%)\end{array}\end{array}$ \\
\hline $\begin{array}{l}\text { Akagawa } \\
\text { et al. } \\
(1971) \\
{[4]}\end{array}$ & $\begin{array}{c}d=9.92 \mathrm{~mm} \\
D=109,225 \mathrm{~mm}\end{array}$ & $\begin{array}{c}0.044<\delta<0.091 \\
0<U_{g}<5 \mathrm{~m} / \mathrm{s} \\
0.35<U_{l}<1.16 \mathrm{~m} / \mathrm{s} \\
\text { Bubbly\&Slug }\end{array}$ & $\begin{array}{l}\text { Frictional pressure drop was measured as } 1.1 \text { to } 1.5 \text { times greater } \\
\text { than that in straight tubes, ceteris paribus. Pressure drop is not a } \\
\text { function of the curvature. Data fitted the Lockhart and Martinelli } \\
\text { correlation. Empirical equations were also provided: } \\
\qquad \frac{\Delta P_{f, T P, c}}{\Delta P_{f, T P, s}}=\frac{\left(1+144 \delta^{1.61}\right)}{\operatorname{Re}_{T P}^{1.4 \delta}} \\
\qquad \operatorname{Re}_{T P}=\frac{U_{l} d}{\left(1-V F_{g}\right) \mu_{l}} \\
\text { where: } \\
\qquad \frac{\Delta P_{f, T P, c}}{\Delta P_{f, l, c}}=\left(1-V F_{g}\right)\left[\left(\frac{2.3 d}{D}\right)-1.4\right] \\
( \pm 35 \%)\end{array}$ \\
\hline $\begin{array}{l}\text { Kasturi } \\
\text { and } \\
\text { Stepanek } \\
(1971) \\
{[68]}\end{array}$ & $\begin{array}{l}d=12.5 \mathrm{~mm} \\
D=665 \mathrm{~mm}\end{array}$ & $\begin{aligned} \delta=0.019 \\
1 \mathrm{E}+3<D e<1 \mathrm{E}+6 \\
\text { Stratified\&Wavy }\end{aligned}$ & Data fitted the Lockhart-Martinelli parameter. \\
\hline $\begin{array}{l}\text { Whalley } \\
(1980) \\
\text { [69] }\end{array}$ & $\begin{array}{c}d=20.2 \mathrm{~mm} \\
D=1000 \mathrm{~mm} \\
B=6\end{array}$ & $\begin{array}{l}\delta=0.019 \\
\text { Stratified \& } \\
\text { Annular }\end{array}$ & $\begin{array}{l}\text { Frictional pressure drop is the dominant pressure drop over the } \\
\text { acceleration and gravity pressure drops. } \\
\text { No correlation provided. }\end{array}$ \\
\hline $\begin{array}{l}\text { Rangachar } \\
\text { yulu and } \\
\text { Davies } \\
(1984) \\
\text { [70] }\end{array}$ & $\begin{array}{l}d=11,13 \mathrm{~mm} \\
1.52<\beta<2.69\end{array}$ & $\begin{array}{c}0.0427<\delta<0.0541 \\
1<v f_{g}<10 \mathrm{~m}^{3} / \mathrm{h} \\
0.04<v f_{l}<0.75 \\
\mathrm{~m}^{3} / \mathrm{h}\end{array}$ & $\begin{array}{l}\text { Correlation also valid for air in glycerol and isobutyl alcohol } \\
\text { solutions. } \\
\emptyset_{g}-1=0.05 R e_{l} \delta^{0.5}\left(\frac{U_{T P}}{C S}\right)^{-0.68}\left(\frac{\mu_{l}^{4} g}{\rho_{l} \sigma_{l}^{3}}\right)^{0.18} \delta^{3.66}\end{array}$ \\
\hline $\begin{array}{l}\text { Xin et al. } \\
(1996) \\
{[8]}\end{array}$ & $\begin{array}{c}d=12.7,19.1,25.4,38 \\
.1 \mathrm{~mm} \\
D=305,609 \mathrm{~mm}\end{array}$ & $\begin{array}{c}0.02<\delta<0.125 \\
0.008<U_{w}<2.2 \\
0.2<U_{g}<50 \\
\text { Bubbly flow }\end{array}$ & $\begin{array}{l}\text { The helix angle, coil and pipe diameters have a marginal effect } \\
\text { on the frictional pressure drop. } \\
\text { For } F_{d}>0.1 \\
\qquad \phi_{l}=\left[1+\frac{\chi}{434.6 F_{d}^{1.7}}\right]\left[1+\frac{20}{\chi}+\frac{1}{\chi^{2}}\right]^{0.5} \\
\text { For } F_{d} \leq 0.1 \\
\qquad \phi_{l}=\left[1+\frac{\chi}{65.45 F_{d}^{0.6}}\right]\left[1+\frac{20}{\chi}+\frac{1}{\chi^{2}}\right]^{0.5} \\
\text { where; } \\
\qquad F_{d}=F r\left(\frac{d}{D}\right)^{0.5}(1+\tan \beta)^{0.2} \\
\qquad F r=\frac{U_{l}^{2}}{g d}\end{array}$ \\
\hline
\end{tabular}




\begin{tabular}{|c|c|c|c|}
\hline & & & $( \pm 35 \%)$ \\
\hline $\begin{array}{c}\text { Mandal } \\
\text { and Das } \\
(2003) \\
{[15]}\end{array}$ & $\begin{aligned} d=10,13 \mathrm{~mm} \\
131<D<2222 \mathrm{~mm} \\
0<\beta<12\end{aligned}$ & $\begin{array}{c}0.046<\delta<0.095 \\
1.5<v f_{g}<52.5 \mathrm{E}-5 \\
3.65<v f_{l}<14.2 \mathrm{E}-5 \\
28<T_{\text {mean }}<32^{\circ} \mathrm{C}\end{array}$ & $\begin{array}{l}\text { The helix angle has no effect on the pressure drop. Empirical } \\
\text { correlation was developed to calculate the two-phase friction } \\
\text { factor. } \\
f_{T P, l} \\
=5.8853 R e_{l}^{-1.1829 \pm 0.0215} R_{g}^{0.952 \pm 0.0142}\left(\frac{\mu_{l}^{4} g}{\rho_{l} \sigma_{l}^{3}}\right)^{0.022 \pm 0.0086} \\
\qquad \delta^{-0.282 \pm 0.0369}\end{array}$ \\
\hline $\begin{array}{l}\text { Murai et } \\
\text { al. }(2006) \\
\quad[16]\end{array}$ & $\begin{array}{c}d=20 \mathrm{~mm} \\
D=540,750 \mathrm{~mm}\end{array}$ & $\begin{array}{c}0.027<\delta<0.04 \\
P=0.101 \mathrm{MPa} \\
1.76<U<5.28 \\
15<T<17^{\circ} \mathrm{C} \\
R e>10^{4} \\
\text { Bubbly/Plug/Slug } \\
\text { flow }\end{array}$ & $\begin{array}{c}\qquad \Delta P_{f, l}=f \rho_{l}(1-V F) \frac{L}{d} \frac{U^{2}}{2} \\
\text { Used Ito's [6] correlation for the single-phase friction factor }\end{array}$ \\
\hline $\begin{array}{l}\text { Saffari et } \\
\text { al. } \\
\text { [17] }\end{array}$ & $\begin{array}{c}d=12,19 \mathrm{~mm} \\
D=200 \mathrm{~mm}\end{array}$ & $\begin{array}{c}0.06<\delta<0.095 \\
P=0.101 \mathrm{MPa} \\
10000<R e<50000 \\
0.03<V F<0.09 \\
\text { Bubbly flow }\end{array}$ & $\begin{array}{l}25 \% \text { reduction in the frictional pressure drop with } V F=0.09 \text { of air } \\
\text { over that of single-phase flow, ceteris paribus. } \\
\text { No correlation provided. }\end{array}$ \\
\hline \multicolumn{4}{|c|}{ Horizontal orientation - Air-Water } \\
\hline $\begin{array}{l}\text { Awwad et } \\
\text { al. (1995) } \\
\quad[20]\end{array}$ & $\begin{array}{c}12.7<d<38.1 \mathrm{~mm} \\
330<D<670 \mathrm{~mm} \\
1<\beta<20\end{array}$ & $\begin{array}{c}0.04<\delta<0.057 \\
0.2<U_{g}<50 \mathrm{~m} / \mathrm{s} \\
0.008<U_{l}<2.2 \mathrm{~m} / \mathrm{s} \\
\text { Bubbly flow }\end{array}$ & $\begin{array}{l}\text { Frictional pressure drop is a function of the flow rate of air and } \\
\text { water and the Lockhart-Martinelli parameter. The helix angle has } \\
\text { almost no effect on the frictional pressure drop whilst the tube } \\
\text { and coil diameters have some effects which diminish at higher } \\
\text { fluid flow rates. } \\
\qquad \phi_{l}=\left[1+\frac{\chi}{C\left(F_{d}\right)^{n 1}}\right]\left[1+\frac{12}{\chi}+\frac{1}{\chi^{2}}\right]^{0.5} \\
\text { where: } \quad F_{d} \leq 0.3, C=7.79 \& n l=0.576 \\
\qquad F_{d}>0.3, C=13.56 \& n l=1.3 \\
( \pm 32 \%)\end{array}$ \\
\hline $\begin{array}{l}\text { Awwad et } \\
\text { al. (1995) } \\
\quad[60]\end{array}$ & $\begin{array}{c}d=25.4 \mathrm{~mm} \\
D=350,660 \mathrm{~mm} \\
1<\beta<20\end{array}$ & $\begin{array}{c}0.04<\delta<0.073 \\
0.2<U_{g}<50 \mathrm{~m} / \mathrm{s} \\
0.008<U_{l}<2.2 \mathrm{~m} / \mathrm{s}\end{array}$ & $\begin{array}{l}\text { Same conclusions as in Awwad et al. [20] } \\
\qquad \begin{array}{c}\phi_{l}=\left[\frac{\chi}{9.63 F_{d}^{0.61}}\right]\left[1+\frac{12}{\chi}+\frac{1}{\chi^{2}}\right]^{0.5} \\
F_{d}=F r \delta^{0.1} \\
( \pm 35 \%)\end{array}\end{array}$ \\
\hline \multicolumn{4}{|c|}{ Coiled flow inverter - Air-Water } \\
\hline $\begin{array}{l}\text { Vashisth } \\
\text { and } \\
\text { Nigam } \\
(2007) \\
{[62]}\end{array}$ & $5<d<15 \mathrm{~mm}$ & $\begin{array}{c}0.05<\delta<0.149 \\
8.33<v f_{g}<100 \mathrm{E}- \\
5 \\
3.33<v f_{l}<1000 \mathrm{E} \\
-6\end{array}$ & $\begin{array}{l}\text { Pressure drop increases by a factor of 1.2-2.5 more than that of a } \\
\text { straight helix. Smaller coil diameters result in higher frictional } \\
\text { pressure drops. } \\
f_{T P}=\frac{29.4 N^{0.16}\left(\frac{D}{d}\right)^{0.19} R e_{g}^{0.06}}{R e_{l}^{0.94}} \quad 400<R e_{l} \leq 9000 \\
f_{T P}=\frac{0.065 N^{0.003} R e_{g}^{0.001}}{\left(\frac{D}{d}\right)^{0.003} \operatorname{Re}_{l}^{0.13}} \quad R e_{l} \geq 10200 \\
( \pm 15 \%)\end{array}$ \\
\hline
\end{tabular}




\begin{tabular}{|c|c|c|c|}
\hline \multicolumn{4}{|c|}{ Annular helicoidal tubes - Air-Water } \\
\hline $\begin{array}{c}\text { Xin et al. } \\
(1997) \\
{[61]}\end{array}$ & $\begin{array}{c}\text { Tube-in-tube } \\
O D_{i t}=6.35,9.525,12 . \\
7 \mathrm{~mm} \\
I D_{o t}=10.21,15.748,2 \\
1.18 \mathrm{~mm} \\
D=114.3,177.8,196 . \\
\quad 85 \mathrm{~mm} \\
\\
\text { Vertical and } \\
\text { Horizontal } \\
\text { orientations }\end{array}$ & $\begin{array}{c}30<R e_{g}<30000 \\
210<R e_{w}<23000\end{array}$ & $\begin{array}{l}\text { Frictional pressure drop is a function of the flow rate of air and } \\
\text { water and the Lockhart-Martinelli parameter, whilst the flow rate } \\
\text { effect diminishes with an increase in the tube diameter. } \\
\qquad \phi_{l}=\left[1+\frac{0.0435 \chi^{1.5}}{F}\right]\left[1+\frac{10.646}{\chi}+\frac{1}{\chi^{2}}\right]^{0.5} \\
\text { where; } \\
\qquad F=F r^{0.9106} e^{0.0458(l n F r)^{2}} \\
F r=\frac{U_{l}^{2}}{g\left(I D_{o t}-O D_{i t}\right)}\end{array}$ \\
\hline \multicolumn{4}{|c|}{ Three-phase: Oil-Air-Water } \\
\hline $\begin{array}{c}\text { Chen and } \\
\text { Guo } \\
(1999) \\
{[63]}\end{array}$ & $\begin{array}{c}d=39 \mathrm{~mm} \\
D=265,522.5 \mathrm{~mm} \\
1<\beta<20\end{array}$ & $\begin{array}{c}0.45<U_{g}<19.02 \mathrm{~m} / \\
\mathrm{s} \\
0.018<U_{w t}<1.85 \mathrm{~m} \\
/ \mathrm{s} \\
0.0141<U_{o}<0.91 \\
\mathrm{~m} / \mathrm{s} \\
15<T_{\text {mean }}<20^{\circ} \mathrm{C} \\
0.1<P<0.5 \mathrm{MPa} \\
V C_{o i}<30 \% \\
V C_{w t}>70 \% \\
\text { Stratified/Oil- } \\
\text { Droplet } \\
\text { Stratified/Oil- } \\
\text { Droplet/Annular } \\
\text { Oil flow }\end{array}$ & $\begin{array}{l}\text { The frictional pressure drop increases with the oil fraction in the } \\
\text { mixture. Coil diameter has no effect on the frictional pressure } \\
\text { drop. } \\
\qquad \phi_{l}^{2}=f(\theta)\left[1-\frac{0.603}{\chi}+\frac{1}{\chi^{2}}\right] \\
\text { where: } \\
\qquad \begin{array}{c}f(\theta)=R^{0.0172}\left(\frac{1526}{G}\right)^{1.596}(\delta)^{0.175}\left(\frac{\mu_{g} \rho_{o}}{\mu_{o} \rho_{o}}\right)^{-1.238}\left(\frac{\mu_{w t} \rho_{o}}{\mu_{o} \rho_{w t}}\right) \\
( \pm 30 \%)\end{array}\end{array}$ \\
\hline \multicolumn{4}{|c|}{ Gas-Non-Newtonian Fluid } \\
\hline $\begin{array}{c}\text { Biswas } \\
\text { and Das } \\
(2008) \\
{[65]}\end{array}$ & $\begin{array}{c}9.3<d<12 \mathrm{~mm} \\
176.2<D<266.7 \mathrm{~m} \\
\mathrm{~m} \\
0<\beta<12\end{array}$ & $\begin{array}{c}0.035<\delta<0.09 \\
0.44<v f_{g}<42.03 \\
\text { E-5 } \\
3.334<v f_{l}<15.00 \\
3 \mathrm{E}-5 \\
28<T_{\text {mean }}<32^{\circ} \mathrm{C} \\
0.2<M C<0.8\end{array}$ & $\begin{array}{l}\text { The effect of the helix angle on the pressure drop was negligible. } \\
\text { Empirical correlation was developed to calculate the two-phase } \\
\text { friction factor. } \\
f_{T P, l} \\
=0.4 R e_{g}^{0.757 \pm 0.025} R e_{l}^{-1.437 \pm 0.059}\left(\frac{\mu_{e f f}^{4} g}{\rho_{l} \sigma_{l}^{3}}\right)^{-0.348 \pm 0.017} \\
\qquad \delta^{0.721 \pm 0.076} \\
(\text { RE } 8 \%)\end{array}$ \\
\hline \multicolumn{4}{|c|}{ SF6-Water } \\
\hline $\begin{array}{l}\text { Czop et } \\
\text { al. (1994) } \\
\quad[64]\end{array}$ & $\begin{array}{c}d=19.8 \mathrm{~mm} \\
D=1170 \mathrm{~mm} \\
\beta=7.27\end{array}$ & $\begin{array}{c}\delta=0.017 \\
0.1<P<1.35 \mathrm{MPa} \\
26000<R e<50000 \\
500<G<3000 \\
\text { Slug \& Bubbly } \\
\text { flow }\end{array}$ & $\begin{array}{l}\text { Significant differences with the Lockhart-Martinelli correlation. } \\
\text { Fairly good agreement with the Chisholm correlation [71]: } \\
\qquad \phi_{l, t t}^{2}=1+\frac{C}{\chi_{t t}}+\frac{1}{\chi_{t t}^{2}} \\
\text { where: } \\
\qquad \chi_{t t}=\frac{1-x}{x}\left(\frac{\rho_{g}}{\rho_{l}}\right)^{0.5} \\
\qquad C=1.5\left[\left(\frac{\rho_{g}}{\rho_{l}}\right)^{0.5}+\left(\frac{\rho_{l}}{\rho_{g}}\right)^{0.5}\right]\end{array}$ \\
\hline
\end{tabular}
coiled tubes 


\section{Nanofluids}

\subsection{Experimental studies}

There is a significant paucity of studies on the pressure drop characteristics of nanofluids in helically coiled or curved tube heat exchangers. Fakoor-Pakdaman et al. [72] reported that the few studies reported on the investigation of nanofluid flow in helically coiled tubes were mainly focused at investigating the heat transfer characteristics with the system parameters. In fact, their study, published in 2013, was the first study to comprehensively investigate the isothermal pressure drop with nanofluids in helically coiled tubes. As reported in Section 1 of the present study, a number of authors have considered the ratio of the resultant pressure drop with nanofluids in a helically coiled tube to that in a straight tube with the base fluid only, to calculate the performance index given in Eq. (1). This is principally used to appraise the application of heat transfer enhancement techniques as a function of the ratios of the heat transfer coefficients and the pressure drops. The latter is particularly relevant to the calculation of the heat exchanger performance, as the use of helical coils and nanofluids could result in a significant increase in the pressure drop (circa 3.5 times) over that of the base fluid in straight tubes [72].

Table 4 summarises the pertinent experimental studies reviewed, categorised according to the nanoparticles and the base fluids investigated. The principal nanoparticles which have been reported by researchers are the oxides of copper and aluminium whilst the base fluids are water and oil.

Most of the researches reviewed in the present study have reported an increase in the nanofluid pressure drop with the nanoparticle concentration and the Reynolds number. This is mainly attributed to the resultant higher relative mixture densities and viscosities [3, 73, 74]. However, most researchers agreed that at low fluid velocities the rate of increase in the pressure drop with the nanoparticle volume concentration was smaller than that at higher fluid velocities. Mukesh Kumar et al. [74] attributed this result to the dominance of the viscosity effects at low Dean numbers. Furthermore, Hashemi and Akhavan-Behabadi [73] reported that the higher rate of chaotic motion and migration of the nanoparticles at increased Reynolds numbers could be the reason for the different rates of pressure drop increases. There are no experimental studies which investigated the pressure drop characteristics of the principle nanofluids, these being the oxides of aluminium and copper dispersed in water, at identical system parameters. However, Hashemi and Akhavan-Behabadi reported that due to the spherical properties of $\mathrm{CuO}$ nanoparticles, reduced levels of friction could result when compared to other nanofluids. This is due to the rolling effect (instead of sliding) between the oil and solid phases.

There is an agreement amongst authors $[18,14]$ that the transitional velocity, and hence the critical Reynolds number of nanofluids will be higher than that of the base fluid. This is due to the higher viscosity of the former. As reported in our review on the two-phase heat transfer characteristics in helically coiled tubes [57] some controversies characterise the studies on nanofluid flow in these tubes. The majority of investigations reviewed in the present study reported a significant appreciation in the pressure drop with nanofluids over that of the base fluid only. Furthermore, the increment in the pressure drop for helical tubes was reported to be higher than that for straight pipes. In view of this, Suresh et al., Fakoor-Pakdaman et al. and Kahani et al. [13, 72, 75] presented correlations for the calculation of the friction factor and pressure drop with nanofluids. These correlations are principally a function of the coil geometry, Dean or Reynolds numbers and the nanoparticle concentration. With a $2 \%$ weight concentration of $\mathrm{CuO}$ nanoparticles in oil, flowing through a helically coiled tube, Hashemi and Akhavan-Behabadi [73] reported an increase in the pressure drop of $20.3 \%$ over that of the 
base fluid only whilst for a straight tube, this was measured as $13.2 \%$. Similarly, for $0.2 \%$ volume concentration of $\mathrm{CuO}$ in water, Kannadasan et al. [18] reported that the friction factor, when compared to water flow only, increased by $24 \%$ and $23 \%$ for horizontal and vertical orientations respectively. However, in contrast to these findings, Suresh et al. and $\mathrm{Wu}$ et al. $[75,14]$ reported that the resultant pressure drop increment with a wide range of nanoparticle concentrations was marginal when compared to that of the base fluid alone. In fact, Wu et al.'s pressure drop results were reasonably predicted by the Ito [6] (laminar) and Seban and McLaughlin [76] (turbulent) equations for single-phase flow in helically coiled tubes. Suresh et al. attributed these results to the nanoscale size of the additive nanoparticles. Furthermore, whilst $\mathrm{Wu}$ et al. [14] reported that, due to their higher viscosity and density, nanofluids resulted in a mitigation of the secondary flow, Mukesh Kumar et al. [3] reported contradictory results. The latter results were attributed to the random motion of the nanoparticles which did not impede the formation of the secondary flow.

The nanofluid pressure drop as a function of the coil geometry was investigated by Kahani et al. [77] and Fakoor-Pakdaman et al. [72] who both reported lower pressure drops with a decrease in the curvature ratio. The pressure drop was also independent of the coil pitch. The former was principally attributed to the weaker centrifugal forces, hence minimising the effects of the secondary flow on the system pressure drop. The sole study which investigated the nanofluid pressure drop as a function of the helical coil orientation was reported by Kannadasan et al. [18]. They reported that the nanofluids in a vertical coil resulted in marginally lower pressure drop increments (over that of pure water) when compared to horizontal coils, ceteris paribus (Fig. 5). However, they failed to critically analyse these results.

497
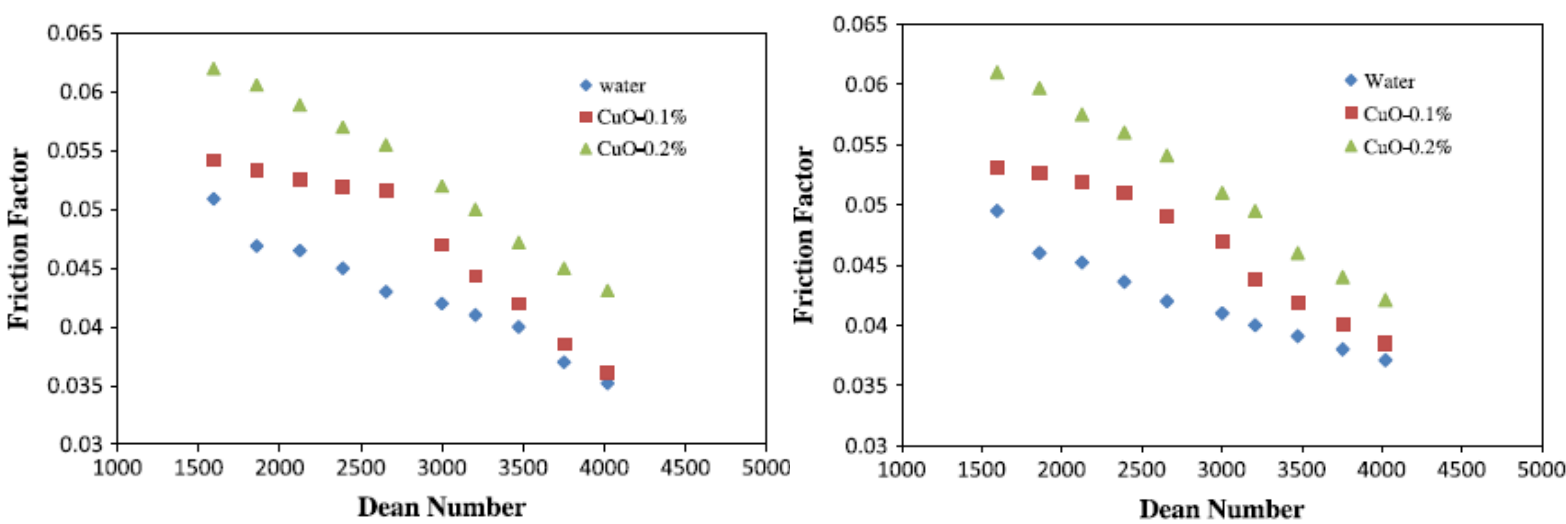

Figure 5: CFD simulation of the CuO nanoparticles in water, friction factor for: (a) Horizontal orientation (b) Vertical orientation (Kannadasan et al. [18], Figs. 7\&8)

\begin{tabular}{|c|c|c|c|c|}
\hline Authors & $\begin{array}{c}\text { Heat exchanger } \\
\text { type/Flow regime }\end{array}$ & Nanofluid & $\begin{array}{c}\text { Volume } \\
\text { or weight } \\
\text { conc. }\end{array}$ & $\begin{array}{c}\text { Main conclusions, proposed correlation and } \\
\text { mean error }\end{array}$ \\
\hline \multicolumn{3}{|c|}{ Copper \& Copper oxide nanoparticles \& Water } \\
\hline $\begin{array}{c}\text { Akbaridoust } \\
\text { et al. (2003) } \\
\text { [78] }\end{array}$ & $\begin{array}{c}\text { Laminar } \\
200<R e<1000\end{array}$ & $\mathrm{Cu} / \mathrm{H}_{2} \mathrm{O}$ & $\begin{array}{c}0.1-0.2 \% \\
(V F)\end{array}$ & $\begin{array}{c}\text { The pressure drop increased with increasing } \\
\text { particle volume concentration and mass flow rate. }\end{array}$ \\
\hline $\begin{array}{c}\text { Suresh et al. } \\
(2011) \\
{[75]}\end{array}$ & $\begin{array}{c}\text { Horizontal with } \\
\text { smooth and } \\
\text { dimpled surface } \\
\text { Turbulent } \\
I D=4.85 \mathrm{~mm} \\
O D=6.3 \mathrm{~mm} \\
2500<R e<6000\end{array}$ & $\mathrm{CuO} / \mathrm{H}_{2} \mathrm{O}$ & $\begin{array}{c}0.1-0.3 \% \\
(V F)\end{array}$ & $\begin{array}{c}\text { Quasi no increase in the pressure drop with } \\
\text { nanofluids over that with distilled water. }\end{array}$ \\
& & $f=0.1648 R e^{0.97}(1+V C)^{107.89}\left(1+\frac{P R}{d}\right)$ \\
\end{tabular}




\begin{tabular}{|c|c|c|c|c|}
\hline $\begin{array}{l}\text { Kannadasan } \\
\text { et al. }(2012) \\
\quad[18]\end{array}$ & $\begin{array}{l}\text { Horizontal \& } \\
\text { vertical } \\
\text { Turbulent } \\
I D=9 \mathrm{~mm} \\
O D=10.5 \mathrm{~mm} \\
D=124 \mathrm{~mm} \\
1600<D e<4000\end{array}$ & $\mathrm{CuO} / \mathrm{H}_{2} \mathrm{O}$ & $\begin{array}{c}0.1-0.2 \% \\
(V C)\end{array}$ & $\begin{array}{c}\text { For both horizontal and vertical coils, an increase in } \\
\text { the friction factor was measured with higher } \\
\text { nanoparticle volume concentrations. Higher Dean } \\
\text { numbers decreased the friction factor. } \\
\text { For } 0.2 \% \text { volume concentration, the friction factor, } \\
\text { when compared to water flow only, increased by } \\
24 \% \text { and } 23 \% \text { for horizontal and vertical } \\
\text { orientations respectively. } \\
\text { No correlation. }\end{array}$ \\
\hline \multicolumn{5}{|c|}{ Copper oxide nanoparticles \& Oil } \\
\hline $\begin{array}{l}\text { Hashemi } \\
\text { and } \\
\text { Akhavan- } \\
\text { Behabadi } \\
(2012) \\
\text { [73] }\end{array}$ & $\begin{array}{c}\text { Horizontal } \\
\text { Laminar } \\
I D=14.37 \mathrm{~mm} \\
D=324 \mathrm{~mm} \\
\operatorname{Re}<125 \\
700<\operatorname{Pr}<2050\end{array}$ & $\mathrm{CuO} / \mathrm{Oil}$ & $\begin{array}{c}0.5-2 \% \\
(W C)\end{array}$ & $\begin{array}{l}\text { The pressure drop increased with increasing } \\
\text { particle volume concentration and Reynolds } \\
\text { numbers. For } 2 \% W C \text {, the pressure drop, when } \\
\text { compared to oil flow only, increased by } 20.3 \% \text {. For } \\
\text { a straight tube this was measured as } 13.2 \% \\
\text { No correlation. }\end{array}$ \\
\hline \multicolumn{5}{|c|}{ Multi-Walled Carbon NanoTubes nanoparticles \& Oil } \\
\hline $\begin{array}{c}\text { Fakoor- } \\
\text { Pakdaman } \\
\text { et al. }(2012) \\
\quad[5]\end{array}$ & $\begin{array}{c}\text { Vertical } \\
\text { Laminar } \\
I D=15.6 \mathrm{~mm} \\
220<D<320 \mathrm{~mm} \\
100<R e<1800 \\
\end{array}$ & $\begin{array}{l}\text { Multi-Walled } \\
\text { Carbon } \\
\text { NanoTubes/Oil }\end{array}$ & $\begin{array}{l}0.1-0.4 \% \\
\quad(W C)\end{array}$ & $\begin{array}{l}\text { Performance index, increases with higher } \\
\text { nanoparticle weight concentrations. } \\
\text { No correlation. }\end{array}$ \\
\hline $\begin{array}{l}\text { Fakoor- } \\
\text { Pakdaman } \\
\text { et al. (2013) } \\
\quad[72]\end{array}$ & $\begin{array}{c}\text { Vertical } \\
\text { Laminar } \\
I D=15.6 \mathrm{~mm} \\
220<D<320 \mathrm{~mm} \\
10<R e<2000\end{array}$ & $\begin{array}{l}\text { Multi-Walled } \\
\text { Carbon } \\
\text { NanoTubes/Oil }\end{array}$ & $\begin{array}{l}0.1-0.4 \% \\
\quad(W C)\end{array}$ & $\begin{array}{l}\text { The pressure drop increased with increasing } \\
\text { particle volume concentration and mass flow rate. } \\
31 \% \text { pressure drop increase over the base fluid at } \\
\text { the highest concentration. Pressure drop is } \\
\text { independent of the coil pitch whilst a decrease in } \\
\text { the curvature ratio results in a lower pressure drop. } \\
\text { Pressure drop in the coiled tube is up to } 2.5 \text { times } \\
\text { higher than that in a straight tube. } \\
\frac{f_{T P}}{f_{b f}}=\left[1+0.031\left(\log D n_{m}\right)^{4}\right](1+10 W C)^{4.9} \\
\text { where: } \\
\qquad D n_{m}=\operatorname{Re}\left\{\delta^{-1}\left[1+\left(\frac{p}{\pi D}\right)^{2}\right]\right\} \\
( \pm 20 \%)\end{array}$ \\
\hline \multicolumn{5}{|c|}{ Aluminium oxide \& titanium dioxide nanoparticles \& Water } \\
\hline $\begin{array}{l}\text { Kahani et } \\
\text { al. (2013a) } \\
\quad[13]\end{array}$ & $\begin{array}{c}\text { Horizontal } \\
\text { Laminar } \\
d=7 \mathrm{~mm} \\
D=70,140 \mathrm{~mm} \\
500<\operatorname{Re}<4500 \\
5.89<P r<8.95 \\
115.3<H e<1311.4\end{array}$ & $\begin{array}{l}\mathrm{Al}_{2} \mathrm{O}_{3} / \mathrm{H}_{2} \mathrm{O} \\
\mathrm{TiO}_{2} / \mathrm{H}_{2} \mathrm{O}\end{array}$ & $\begin{array}{l}0.25-1.0 \% \\
\quad(V C)\end{array}$ & $\begin{array}{l}\text { The pressure drop increased with increasing } \\
\text { particle volume concentration and mass flow rate. } \\
\qquad \Delta P_{T P}=5.584 H e^{1.36} V F^{0.446} d^{0.163} R A^{2} \\
\text { where: } \\
\qquad H e=D e\left[1+\left(\frac{p}{2 \pi D}\right)^{2}\right]^{0.5}\end{array}$ \\
\hline $\begin{array}{l}\text { Kahani et } \\
\text { al. (2013b) } \\
\quad[77]\end{array}$ & $\begin{array}{c}\text { Horizontal } \\
\text { Laminar } \\
d=7 \mathrm{~mm} \\
D=70,140 \mathrm{~mm} \\
500<\operatorname{Re}<4500 \\
5.89<\operatorname{Pr}<8.95 \\
115.3<\mathrm{He}<1311.4\end{array}$ & $\mathrm{Al}_{2} \mathrm{O}_{3} / \mathrm{H}_{2} \mathrm{O}$ & $\begin{array}{l}0.25-1.0 \% \\
\quad(V C)\end{array}$ & $\begin{array}{l}\text { The pressure drop increased with increasing } \\
\text { particle volume concentration and mass flow rate. } \\
\text { A decrease in the curvature ratio results in a lower } \\
\text { pressure drop, whilst the coil pitch had a minimal } \\
\text { effect on the pressure drop. } \\
\text { No correlation. }\end{array}$ \\
\hline $\begin{array}{l}\text { Mukesh } \\
\text { Kumar et al. } \\
(2013)\end{array}$ & $\begin{array}{c}\text { Laminar } \\
5100<\operatorname{Re}<8700 \\
I D=9 \mathrm{~mm} \\
\end{array}$ & $\mathrm{Al}_{2} \mathrm{O}_{3} / \mathrm{H}_{2} \mathrm{O}$ & $\begin{array}{c}0.1-0.8 \% \\
(V C)\end{array}$ & $\begin{array}{l}\text { Generally, the pressure drop increased with } \\
\text { increasing particle volume concentration and mass }\end{array}$ \\
\hline
\end{tabular}




\begin{tabular}{|c|c|c|c|c|}
\hline [3] & $\begin{aligned} O D & =10.5 \mathrm{~mm} \\
D & =93 \mathrm{~mm}\end{aligned}$ & & & $\begin{array}{l}\text { flow rate. Rate of pressure drop increase was higher } \\
\text { when the Dean number increased. } \\
\text { No correlation. }\end{array}$ \\
\hline $\begin{array}{c}\text { Wu et al. } \\
\text { (2013) } \\
{[14]}\end{array}$ & $\begin{array}{c}\text { Double pipe } \\
\text { Laminar \& } \\
\text { Turbulent } \\
I D_{i t}=13.28 \mathrm{~mm} \\
I D_{o t}=26 \mathrm{~mm} \\
D=254 \mathrm{~mm} \\
800<R e<10000\end{array}$ & $\mathrm{Al}_{2} \mathrm{O}_{3} / \mathrm{H}_{2} \mathrm{O}$ & $\begin{array}{c}0.78- \\
7.04 \% \\
(W C)\end{array}$ & $\begin{array}{l}\text { Mitigation of secondary flow with nanofluids. } \\
\text { Friction factor decreases with higher Reynolds } \\
\text { numbers for laminar flow while it increases slowly } \\
\text { for higher Reynolds numbers in turbulent flow. } \\
\text { Their friction factor was predicted through the use } \\
\text { of the Ito [6] (laminar) and Seban and McLaughlin } \\
\text { [76] (turbulent) equations for single-phase flow. } \\
\qquad( \pm 30 \%)\end{array}$ \\
\hline $\begin{array}{l}\text { Mukesh } \\
\text { Kumar et al. } \\
\text { (2014) } \\
\text { [74] }\end{array}$ & $\begin{array}{c}\text { Laminar } \\
0.03<\dot{m}<0.05 \\
1600<D e<2700 \\
I D=10 \mathrm{~mm} \\
O D=11.5 \mathrm{~mm} \\
D=93 \mathrm{~mm}\end{array}$ & $\mathrm{Al}_{2} \mathrm{O}_{3} / \mathrm{H}_{2} \mathrm{O}$ & $\begin{array}{c}0.1-0.8 \% \\
\quad(V C)\end{array}$ & $\begin{array}{l}\text { Generally, the pressure drop increased with } \\
\text { increasing particle volume concentration and mass } \\
\text { flow rate. Rate of pressure drop increase was higher } \\
\text { when the Dean number increased. } \\
\text { Hence, no significant increase in the pressured drop } \\
\text { with } 0.1 \% \text { and } 0.4 \% \text { nanofluid particle volume } \\
\text { concentration. } \\
\text { No correlation. }\end{array}$ \\
\hline
\end{tabular}

Table 4: Review of experimental studies of the pressure drop characteristics of nanofluids in helically coiled tubes

\subsection{Numerical Studies}

Research on the pressure drop and the general thermo-physical properties of nanofluids in helically coiled heat exchangers is a relatively new development. In fact, the earliest research in the pertinent literature was reported by Sasmito et al. [23] in 2011. The ANSYS Fluent commercial software package was used in all of the studies reviewed and summarised in this section. Therefore, the fluid flow and heat transfer governing equations, given in Eqs. (14-16), were solved to measure the pressure drop and temperature distribution along the helically coiled tubes.

\section{Continuity:}

$\frac{\partial \rho}{\partial T}+\nabla \cdot(\rho V)=0$

Momentum:

$\rho \frac{\delta V}{\delta T}+\nabla \cdot \tau_{i j}-\nabla P+\rho F B=0$

Energy:

$\rho \frac{D e}{\delta T}+\rho(\nabla \cdot V)=\frac{\partial Q}{\partial T}-\nabla \cdot Q+\phi_{d}$

where $V$ is the fluid velocity, $F B$ are the body forces, $\phi_{d}$ is the energy dissipation term and $Q$ is the heat transfer by conduction. The numerical analysis studies reviewed in this section assumed that the nanofluid flow through the tubes is incompressible, single-phase and fully developed, both hydrodynamically and thermally. The SIMPLEC algorithm was used by a number of studies to solve the flow field [21,31], whilst for turbulent flow modelling, the Standard Turbulence $k-\varepsilon$ model as proposed by Launder and Spalding, was used [79]. The 
546

547

548

549

550

551

552

553

554

555

556

557

558

559

560

561

562

563

564

565

566

567

568

569

570

571

572

thermo-physical properties of the nanofluids were obtained using the equations given in Eqs. $(17-28)$ [21, 31].

Density:

$\rho_{n f}=(1-V F) \rho_{b f}+V F \rho_{n p}$

Heat capacity:

$$
\left(\rho C_{p}\right)_{n f}=(1-V F)\left(\rho C_{p}\right)_{b f}+V F\left(\rho C_{p}\right)_{n p}
$$

Effective thermal conductivity:

$k_{\text {eff }}=k_{\text {static }}+k_{\text {Brownian }}$

Static thermal conductivity:

$k_{\text {static }}=k_{b f}\left[\frac{k_{n p}+2 k_{b f}-2\left(k_{b f}-k_{n p}\right) V F}{k_{n p}+2 k_{b f}+\left(k_{b f}-k_{n p}\right) V F}\right]$

Brownian thermal conductivity:

$k_{\text {Brownian }}=5 E 4 \beta V F \rho_{b f} C_{p, b f} \sqrt{\frac{\kappa T}{2 \rho_{n p} r d_{n p}} f(T, V F)}$

where the Boltzmann constant, $\kappa=1.3807 \mathrm{E}-23 \mathrm{~J} / \mathrm{K}$

Modelling function for $\mathrm{CuO}, 1 \% \leq V F \leq 6 \%, \beta$ :

$\beta=9.881(100 V F)^{-0.9446}$

Modelling function for $\mathrm{Al}_{2} \mathrm{O}_{3}, 1 \% \leq V F \leq 10 \%, \beta$ :

$\beta=8.4407(100 V F)^{-1.07304}$

Modelling function for $\mathrm{ZnO}, 1 \% \leq V F \leq 7 \%, \beta$ :

$\beta=8.4407(100 V F)^{-1.07304}$

Modelling function for $\mathrm{SiO}_{2}, 1 \% \leq V F \leq 10 \%, \beta$ :

$\beta=1.9526(100 V F)^{-1.4594}$

Modelling function, $f(T, V F)$ :

$$
f(T, V F)=(2.8217 E-2) V F+(3.917 E-3)\left(\frac{T}{T_{o}}\right)+(V F(-3.0699 E-2)-(3.91123 E-3))
$$

Dynamic viscosity: 
$\frac{\mu_{e f f}}{\mu_{b f}}=\frac{1}{1-34.87\left(\frac{d i_{n p}}{d i_{b f}}\right)^{-0.3} V F^{1.03}}$

577

578

579

580

581

582

583

584

585

586

587

588

589

590

591

592

593

594

595

596

597

598

599

600

601

602

603

604

605

606

607

608

609

610

611

612

613

614

615

616

617

618

619

where the equivalent diameter of the base fluid molecule is:

$d i_{b f}=\left(\frac{6 M}{N \pi \rho_{b f}}\right)$

Table 5 summarises the numerical studies on the pressure drop characteristics with nanofluid laminar and turbulent flow in helically coiled tubes. The studies summarised in this section are in reasonable agreement with the data reported in the experimental studies reviewed in Section 4.1. Furthermore, some controversy also characterises the reviewed numerical studies. Hence, whilst a number of authors $[21,22,80]$ reported an increase in the frictional pressure drop with higher nanoparticle volume concentrations as well as higher nanofluid pressure drops over that of the base fluid only, Sasmito et al. [23] reported that at a nanoparticle volume concentration of $1 \%$, the calculated pressure drop was lower than that for pure water. Sasmito et al. attributed these results to the fact that at low volume concentrations, the nanoparticles have a minimal effect on the fluid viscosity, whereas the temperature effects on the nanofluid thermo-physical properties are more significant. Intriguingly, Aly [30] also reported that the aluminium oxide nanoparticles with a maximum volume concentration of $2 \%$ did not result in an increase to the resultant pressure drop. Therefore, their data was in reasonable agreement with the single-phase friction factor correlations by Mishra and Gupta and Ito [7, 6]. Similar results were also reported by Suresh et al. and Wu et al. [75, 14] through their experimental investigations. One of the advantages of numerical simulations is the minimal cost incurred for each simulation. Hence, Narrein and Mohammed [21] were able to investigate the flow characteristics of a combination of oil, ethylene glycol and water based nanofluids. They reported that due to the high viscosities of oil based nanofluids, the latter resulted in the highest calculated pressure drop when compared to ethylene glycol and water based nanofluids. Narrein and Mohammed also reported higher pressure drops with decreasing nanoparticle diameters which were more intense at higher fluid velocities. These results were attributed to the resultant increase in the fluid viscosity which could result in higher wall shear stresses.

Through their numerical investigations, Elsayed et al. [29] and Moraveji and Hejazian [80] presented correlations for the prediction of the friction factor. The former's correlation takes the form of a ratio of the nanofluid flow pressure drop in a helically coiled tube to that in a straight tube, ceteris paribus. This correlation is a function of the fluid properties, represented through a modified Reynolds number and the tube geometry, represented through the curvature ratio. The correlation presented by the latter authors is markedly different as it is not a function of the coil geometry. In fact, it is a sole function of the fluid properties, represented through the nanoparticle volume concentration and the Reynolds number.

Mohammed and Narrein [31] and Aly [30] investigated the nanofluid pressure drop characteristics with the coil geometry. In agreement with the experimental results reported by Kahani et al. [13] and Fakoor-Pakdaman et al. [5], an increase in the nanofluid frictional pressure drop was reported with a reduction in the coil diameter, whilst the pressure drop decreased with larger tube diameters. As reported in Section 4.1, these results can be attributed to the reduction in the centrifugal forces with larger helix diameters. As illustrated in Fig. 6, the pressure drop was also reported to be independent of the helix pitch. 

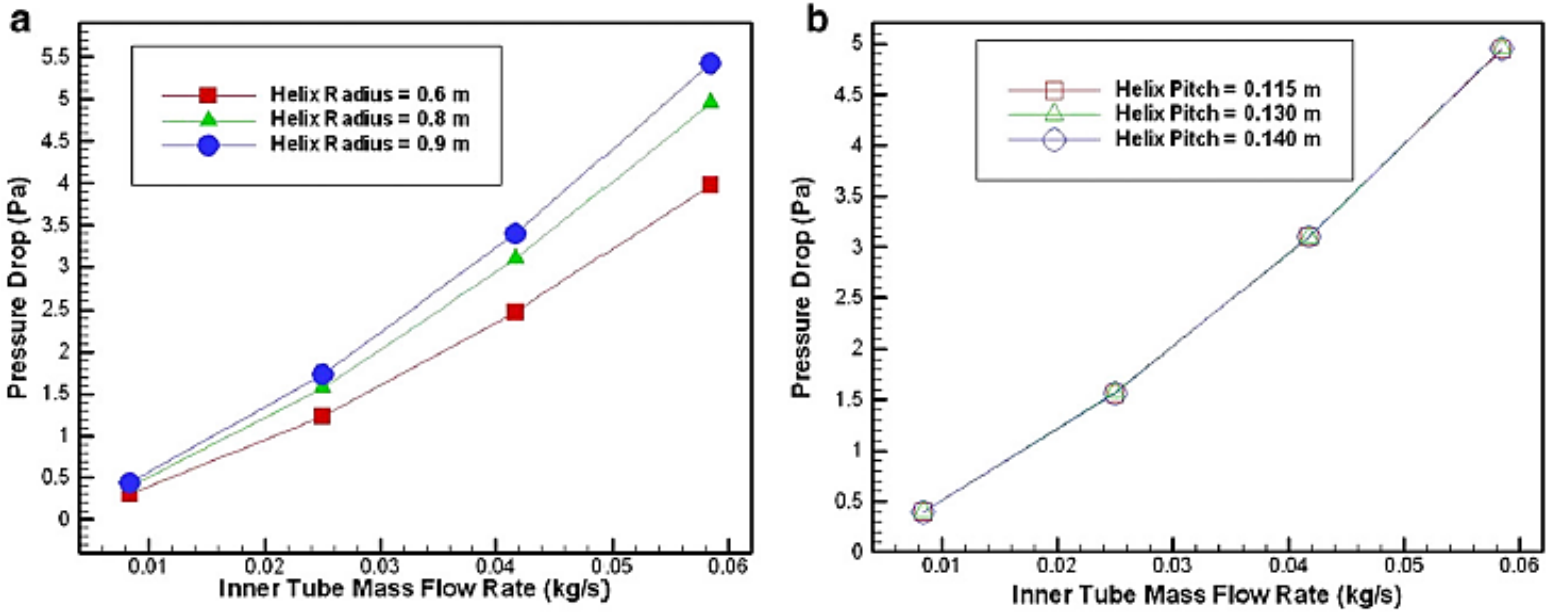

Figure 6: CFD simulation of the $\mathrm{CuO}$ nanoparticles in water, pressure drop for: different helix radii (a), pitches (b) (Mohammed and Narrein [31], Fig. 7a\&b)

\begin{tabular}{|c|c|c|c|c|}
\hline Authors & $\begin{array}{l}\text { Heat exchanger } \\
\text { type / Flow } \\
\text { regime }\end{array}$ & Nanofluid & $\begin{array}{l}\text { Volume } \\
\text { or } \\
\text { Weight } \\
\text { Concent } \\
\text { ration } \\
\end{array}$ & $\begin{array}{l}\text { Main conclusions, proposed correlation and } \\
\text { mean error }\end{array}$ \\
\hline $\begin{array}{c}\text { Sasmito et } \\
\text { al. (2011) } \\
{[23]}\end{array}$ & $\begin{array}{l}\text { Square tubes } \\
\text { Laminar }\end{array}$ & $\begin{array}{l}\mathrm{Al}_{2} \mathrm{O}_{3} / \mathrm{H}_{2} \mathrm{O} \\
\mathrm{CuO} / \mathrm{H}_{2} \mathrm{O}\end{array}$ & $\begin{array}{l}0-1 \% \\
(V C)\end{array}$ & $\begin{array}{l}\text { Helical coil resulted in the highest pressure drop } \\
\text { when compared to straight, conical and in-plane } \\
\text { coiled tubes. } \\
\text { At } 1 \% \text { nanoparticle concentration, the pressure } \\
\text { drop was lower than that for water. } \\
\text { No correlation. }\end{array}$ \\
\hline $\begin{array}{l}\text { Jamshidi et } \\
\text { al. (2012) } \\
{[22]}\end{array}$ & $\begin{array}{c}\text { Laminar } \\
1700<\operatorname{Re}<2500\end{array}$ & $\mathrm{Al}_{2} \mathrm{O}_{3} / \mathrm{H}_{2} \mathrm{O}$ & $\begin{array}{l}1-3 \% \\
(V C)\end{array}$ & $\begin{array}{c}\text { Friction factor increased with higher nanoparticle } \\
\text { volume concentrations and lower Reynolds } \\
\text { numbers. } \\
\text { No correlation. }\end{array}$ \\
\hline $\begin{array}{c}\text { Mohammed } \\
\text { and Narrein } \\
\text { (2012) } \\
{[31]}\end{array}$ & $\begin{array}{c}\text { Laminar } \\
0.01<\dot{m}<0.06 \\
d=32,42,52 \mathrm{~mm} \\
D=600,800,900 \\
\mathrm{~mm}\end{array}$ & $\mathrm{CuO} / \mathrm{H}_{2} \mathrm{O}$ & $\begin{array}{l}4 \% \\
(V C)\end{array}$ & $\begin{array}{l}\text { Pressure drop increased with a reduction in the } \\
\text { coil diameter and decreased with larger tube } \\
\text { diameters. } \\
\text { No correlation. }\end{array}$ \\
\hline $\begin{array}{c}\text { Narrein and } \\
\text { Mohammed } \\
\text { (2013) } \\
{[21]}\end{array}$ & $\begin{array}{c}\text { Laminar } \\
0.01<\dot{m}<0.06\end{array}$ & $\begin{array}{c}\mathrm{CuO} / \mathrm{H}_{2} \mathrm{O} / \text { Engine } \\
\mathrm{Oil} / \text { Ethylene } \\
\text { glycol } \\
\mathrm{Al}_{2} \mathrm{O}_{3} / \mathrm{H}_{2} \mathrm{O} / \text { Engin } \\
\text { e Oil/Ethylene } \\
\text { glycol } \\
\mathrm{ZnO} / \mathrm{H}_{2} \mathrm{O} / \text { Engine } \\
\mathrm{Oil} / \text { Ethylene } \\
\text { glycol } \\
\mathrm{SiO}_{2} / \mathrm{H}_{2} \mathrm{O} / \text { Engine } \\
\text { Oil/Ethylene } \\
\text { glycol }\end{array}$ & $\begin{array}{l}1-4 \% \\
(V C)\end{array}$ & $\begin{array}{l}\text { Due to the different densities, } \mathrm{SiO}_{2} \text { had the } \\
\text { highest pressure drop followed by } \mathrm{Al}_{2} \mathrm{O}_{3}, \mathrm{ZnO} \text {, } \\
\qquad \mathrm{CuO} \text {. } \\
\text { Due to higher viscosities, pressure drop increased } \\
\text { with higher nanoparticle concentrations and } \\
\text { decreasing nanoparticle diameters. Due to higher } \\
\text { wall shear stresses this effect is more intense at } \\
\text { higher fluid velocities. } \\
\text { Pressure drop for oil based nanofluids resulted in } \\
\text { the highest pressure drop followed by ethylene } \\
\text { glycol and water based nanofluids. } \\
\text { No correlation. }\end{array}$ \\
\hline
\end{tabular}




\begin{tabular}{|c|c|c|c|c|}
\hline $\begin{array}{c}\text { Elsayed et } \\
\text { al. (2014) } \\
{[29]}\end{array}$ & $\begin{array}{c}\text { Turbulent } \\
20000<R e<50000\end{array}$ & $\mathrm{Al}_{2} \mathrm{O}_{3} / \mathrm{H}_{2} \mathrm{O}$ & $\begin{array}{l}0-3 \% \\
(V C)\end{array}$ & $\begin{array}{l}\text { Pressure drop in coils with nanofluids was } \\
\text { measured as a ratio to that of water in a straight } \\
\text { tube. } \\
\frac{f_{n f, c}}{f_{b f, s}}=\frac{f_{n f, c}}{f_{n f, s}}=\frac{4\left(0.08 R e_{n f}^{-0.25}+0.012 \delta^{0.5}\right)}{0.316 R e_{n f}^{-0.25}} \\
( \pm 5 \%)\end{array}$ \\
\hline $\begin{array}{c}\text { Aly (2014) } \\
\text { [30] }\end{array}$ & $\begin{array}{c}\text { Tube-in-tube } \\
\text { Turbulent } \\
D=180,240,300 \mathrm{~m} \\
\mathrm{~m} \\
2<v f_{i t}<5 \mathrm{LPM} \\
10<v f_{i t}<25 \mathrm{LPM}\end{array}$ & $\mathrm{Al}_{2} \mathrm{O}_{3} / \mathrm{H}_{2} \mathrm{O}$ & $\begin{array}{c}05-2 \% \\
(V C)\end{array}$ & $\begin{array}{l}\text { Single-phase friction factor correlations by Ito } \\
\text { and Mishra and Gupta are also valid for } \\
\text { nanofluids. } \\
\text { Friction factor increased with curvature ratios. } \\
\text { No pressure drop increase with nanoparticle } \\
\text { volume concentration. } \\
\text { No correlation. }\end{array}$ \\
\hline $\begin{array}{l}\text { Moraveji } \\
\text { and } \\
\text { Hejazian } \\
(2014) \\
{[80]}\end{array}$ & $\begin{array}{c}\text { Laminar } \\
d=14.4 \mathrm{~mm} \\
D=324 \mathrm{~mm}\end{array}$ & $\mathrm{CuO} / \mathrm{Oil}$ & $\begin{array}{c}0.5-2 \% \\
(W C)\end{array}$ & $\begin{array}{l}\text { Pressure drop with } 2 \% \text { nanoparticles is } 11 \% \\
\text { higher than that for the base fluid, ceteris paribus. } \\
\text { Pressure drop for the base fluid in the helical coil } \\
\text { was } 3 \text { times higher than that in a straight tube. } \\
\qquad f=1.9254 R e^{-1.223}(1+V C)^{0.00781} \\
\qquad( \pm 15 \%)\end{array}$ \\
\hline
\end{tabular}

Table 5: Review of numerical studies on the pressure drop characteristics of nanofluids in helically coiled tubes

\section{Scope for further research}

As discussed in Section 3, recent studies have suggested that the introduction of small air bubbles $(b<0.5 \mathrm{~mm})$ in turbulent flow could result in a substantial reduction of the frictional pressure drop over that of pure water. A number of studies have investigated this concept for two-phase flow in straight tubes [66, 67] whilst Saffari et al. [17] presented the sole study for helically coiled tubes. Saffari et al.'s conclusions are in substantial disagreement with the findings reported by the majority of investigations on air-water two-phase flow, where the introduction of the second phase was reported to enhance the frictional pressure drop. In fact, the pressure drop multiplier in Eq. (3), as originally defined by Lockhart and Martinelli, was typically reported to be in excess of unity. Such evident controversies should be addressed through further research on the frictional pressure drop due to bubbly air-water two-phase flows in coiled tubes.

As reported in a study published by one of the authors of the present study [81], airwater two-phase flow through helically coiled tube heat exchangers characterises many modern condensing sealed heating systems. Bubbly flow finds its origins in the supersaturated conditions at the heat exchanger wall. Whilst numerous studies investigated the air-water bubbly flow pressure drop, these studies were developed through the insertion of artificial bubbles. This presents significant scope for further research on the bubbly flow two-phase frictional pressure drops, where bubbles nucleate and detach at the tube wall and therefore, the volumetric void fraction at the return and flow ends of the heat exchanger would be dissimilar. Moreover, in view of the fact that numerous studies have suggested enhanced heat transfer coefficients with the addition of nanoparticles to water [75, 18], there is scope for further research on the three-phase air-water-nanoparticles frictional pressure drop in helically coiled tube heat exchangers.

Due to the recent development of nanofluids as a means for the enhancement of the fluid heat transfer characteristics, there is ample scope for further research in this field of study. The majority of the pertinent studies available in the open literature have focused their 
investigations on the resultant heat transfer characteristics. This is evidenced by the paucity of correlations presented for the calculation of the frictional pressure drop when compared to those available for the heat transfer coefficient [57]. Further investigations should be developed to address the conflicting results for the impact of the nanoparticle concentration on the frictional pressure drop as outlined in Section 4. Studies should also be developed for the purpose of investigating the frictional pressure drop as a sole function of the type of nanoparticles. Such studies are deemed necessary in view of the conclusions made by Hashemi and Akhavan-Behabadi [73] who reported that due to their typical spherical shape, copper oxide nanoparticles could yield lower frictional pressure drops. The open literature presents a single study on the two-phase frictional pressure drop as a function of the coil orientation [18], where horizontal coils were reported to yield marginally higher pressure drops. However, the authors failed to provide a detailed appraisal for the latter results. Furthermore, this study was developed with copper oxide nanoparticles in water and hence, further studies are required to investigate the impact of the coil orientation with widely used nanoparticles and base fluids, such as aluminium oxide and oil respectively. Moreover, the pertinent literature failed to comprehensively investigate the distribution of the secondary phase (nanoparticles) in coiled tubes. Therefore, whilst Wu et al. [14] reported that nanofluid flow in coiled tubes did not yield a significant phase separation, no other relevant studies investigated this pertinent flow characteristic. Such avenues for future fundamental research will complement and facilitate the research and development of high efficiency heat exchangers as well as open new opportunities for industry-led heat exchanger tube design initiatives, whereby the distribution of the secondary phase could be manipulated for optimised system efficiencies.

\section{Conclusions}

This paper has provided a review on all the investigations available in the pertinent literature on the two-phase pressure drop characteristics in helically coiled tubes. Therefore the relevant investigations on steam-water flow boiling, R-134a evaporation and condensation, air-water flow and nanofluids have been critically reviewed. The correlations for the calculation of the frictional two-phase pressure drop were also tabulated with the corresponding system parameters. Whilst being more complex than single-phase flow, two-phase flow is more relevant to numerous engineering applications. Therefore a comprehensive understanding of the two-phase pressure drop is necessary to ensure that no excessive, energy consuming, pumping power is required. The pertinent conclusions outlined in the current study can be summarised through the following points:

- For steam-water flow boiling, the frictional pressure drop increases with the vapour quality and mass flux whilst it decreases with higher system pressures. The appreciation of the frictional pressure drop with the vapour quality is more significant at qualities below 0.3 . The curvature ratio does not appear to have a significant influence on the two-phase flow boiling frictional pressure drop multiplier whilst there is some controversy surrounding the influence of the coil orientation and heat flux. Some studies have correlated their data to widely cited correlations for straight tubes such as those given by: Lockhart and Martinelli, Martinelli and Nelson and Chen.

- For R-134-a evaporation and condensation in helically coiled tubes, the curvature ratio appears to have some impact on the resultant frictional pressure drop for R-134a flow in non-miniature helically coiled tubes $(d>1 \mathrm{~mm})$. The pertinent investigations have also concluded that the frictional pressure drop increases with higher vapour qualities and refrigerant mass fluxes, whilst the tube orientation has no significant impact on the 
pressure drop. The majority of the correlations presented are a function of the Lockhart and Martinelli parameter.

- The pertinent literature presents numerous correlations for the prediction of the twophase frictional pressure drop with air-water bubbly flow. The majority of investigations have correlated their data using the original or modified Lockhart and Martinelli correlation for straight tubes, whilst other authors presented their own empirical correlations. The early investigations reported the two-phase pressure drop to be independent of the coil design parameters such as the curvature ratio and the helix angle, whilst more recent studies have suggested a marginal impact on the two-phase pressure drop by the latter parameters. The frictional pressure drop as a function of the air volumetric void fraction remains indeterminate due to conflicting results.

- Few correlations are available to calculate the frictional pressure drop with nanofluids. The majority of experimental and numerical investigations on nanofluids flowing in helically coiled tubes have reported a significant increment (up to 3.5 times) in the frictional two-phase pressure drop over that of pure water in straight tubes. Such conclusions were mainly attributed to the higher relative mixtures and densities as well as the secondary flow formed in curved tubes. Due to the dominance of the viscosity effects at low fluid velocities, the impact of the nanoparticle concentration on the twophase frictional pressure drop is stronger at higher Reynolds numbers. The frictional pressure drop was also reported to be a function of the curvature ratio and the coil orientation with marginally larger pressure drops for horizontal coils. Controversy surrounds the impact of nanofluids on the frictional pressure drop, where some investigations reported a decrease in the resultant pressure drop while other studies reported the pressure drop to be quasi-identical to that with pure water in coiled tubes.

This paper has also outlined areas for further research, principally in the fields of air-water and nanofluids two-phase flows and three-phase air-water-nanoparticles flow. Such studies could take the form of fundamental research as well as industrial research and development initiatives with the aim of enhancing the system efficiencies through the reduction of the two-phase pressure drop.

\section{Acknowledgments}

The authors of the current investigation would like to thank the University of Central Lancashire UK, for facilitating the completion of this study as well as the various authors who have been contacted during the course of this study.

\section{Notation List}
A Heat transfer area $\left(\mathrm{m}^{2}\right)$
$b \quad$ Bubble diameter $(\mathrm{m})$
bf Base fluid (-)
$c_{p} \quad$ Specific heat $(\mathrm{J} / \mathrm{kgK})$
$C$ Constant depending on the flow condition of the vapour and liquid i.e. 5 for laminar and 20 for turbulent flows (-)
CS Stratified speed of sound $(\mathrm{m} / \mathrm{h})$
$d \quad$ Tube diameter $(\mathrm{m})$
$D \quad$ Helix diameter (m)
De Dean number (-)
$D i \quad$ Diameter of nanoparticle (m) 
E Corrugation depth (m)

$756 f \quad$ Friction factor (-)

$757 \quad F r \quad$ Froude number $(-)$

$758 \quad F B \quad$ Body forces $(\mathrm{N})$

$759 g \quad$ Acceleration due to gravity $(\mathrm{m} / \mathrm{s})$

$760 \quad G \quad$ Mass flux $\left(\mathrm{kg} / \mathrm{m}^{2} \mathrm{~s}\right)$

$761 \quad h^{*} \quad$ Mean heat transfer coefficient after applying enhancement techniques (Nanoparticles

762 and helical coils) $\left(\mathrm{W} / \mathrm{m}^{2} \mathrm{~K}\right)$

$763 h_{s t} \quad$ Mean heat transfer coefficient inside a straight tube with base fluid only

764 He Helical coil number (-)

$765 \quad H \quad$ Coil vertical height (m)

$766 \quad H D \quad$ Hydraulic diameter (m)

767 ID Inner tube diameter $(\mathrm{m})$

$768 \quad k \quad$ Thermal conductivity $(\mathrm{W} / \mathrm{mK})$

$769 L \quad L \quad$ Length (m)

$770 \dot{m} \quad$ Mass flow rate $(\mathrm{kg} / \mathrm{s})$

$771 M \quad$ Molecular weight $(\mathrm{mol} / \mathrm{g})$

$772 \quad M C \quad$ Mass concentration $\left(\mathrm{kg} / \mathrm{m}^{3}\right)$

$773 N \quad$ Number of bends (-)

774 OD Outside tube diameter (m)

$775 \quad p \quad$ Pitch (m)

$776 \quad P \quad$ System pressure (-)

$777 \quad P r \quad$ Prandtl number (-)

$778 \quad P I \quad$ Performance index (-)

$779 \quad P R \quad$ Pitch ratio (-)

$780 \Delta P^{*} \quad$ Mean pressure drop after applying enhancement techniques (Nanoparticles and helical coils) $(\mathrm{Pa})$

$783 \quad \triangle P_{T P} \quad$ Two-phase frictional pressure drop $(\mathrm{Pa})$

$784 \quad q \quad$ Heat flux $\left(\mathrm{kW} / \mathrm{m}^{2}\right)$

$785 Q \quad$ Heating power $(\mathrm{kW})$

$786 r d \quad$ Radius of nanoparticle $(\mathrm{m})$

787 Re Reynolds number (-)

$788 \quad R A \quad$ Adjusted correlation coefficient (-)

$789 \quad R E \quad$ Average relative error (\%)

$790 \quad R M S$ Root mean square (-)

$791 \quad S \quad$ Slip ratio (-)

$792 \quad S F \quad$ Shape factors (-)

$793 \quad T \quad$ Temperature $\left({ }^{0} \mathrm{C}\right)$

$794 U$ Superficial velocity $(\mathrm{m} / \mathrm{s})$

$795 v \quad$ Specific volume $\left(\mathrm{m}^{3} / \mathrm{kg}\right)$

796 vf Volume flow rate $\left(\mathrm{m}^{3} / \mathrm{s}\right)$

$797 \quad V \quad$ Flow velocity $(\mathrm{m} / \mathrm{s})$

$798 \quad V C \quad$ Volume concentration (-)

$799 \quad V F \quad$ Void fraction (-)

$800 W C \quad$ Mass concentration as fraction (-)

$801 x \quad$ Steam quality (-)

$802 \quad z \quad$ Vertical elevation (m) 


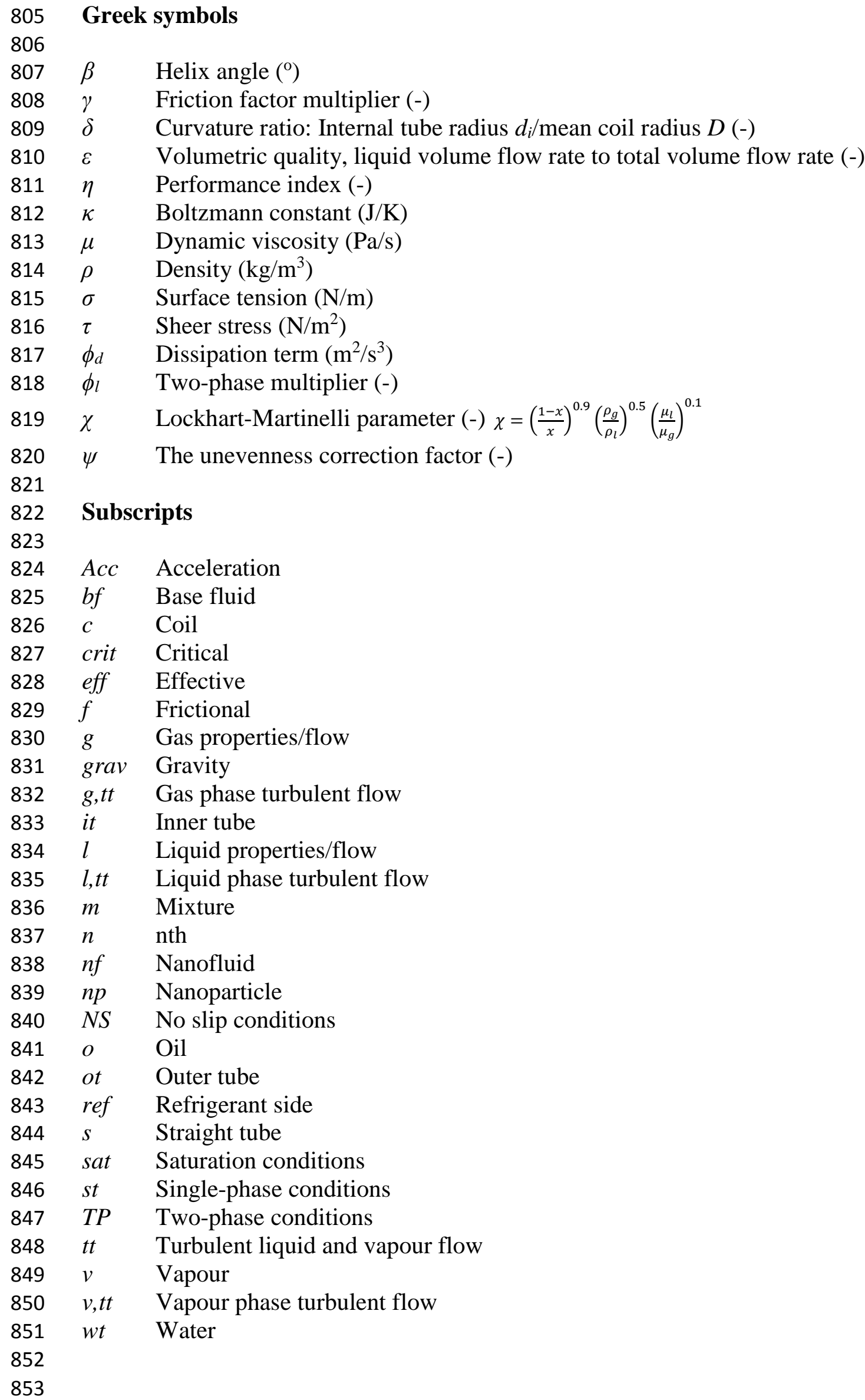




\section{Reference List}

1. Goering D.J., Humphrey J.A.C, Greif R., 1997, The dual influence of curvature and buoyancy in fully developed tube flows, International Journal of Heat and Mass Transfer, 40, pp. 2187-2199

2. Pabhanjan D.G., Raghavan G.S.V., Rennie T.J., 2002, Comparison of heat transfer rates between a straight tube heat exchanger and a helically coiled heat exchanger, Int. Comm. Heat Mass Transfer, 29 (2) pp. 185-191

3. Mukesh Kumar P.C., Kumar J., Suresh S., 2013, Experimental investigation on convective heat transfer and friction factor in a helically coiled tube with $\mathrm{Al}_{2} \mathrm{O}_{3} /$ water nanofluid, Journal of Mechanical Science and Technology, 27 (1), pp. 239-245

4. Akagawa K., Tadashi S., Minoru U., 1971, Study on a gas-liquid two-phase flow in helically coiled tubes, Bulletin of JSME, 14 (72), pp. 564-571

5. Fakoor-Pakdaman M., Akhavan-Behabadi M.A., Razi P., 2012, An experimental investigation on thermo-physical properties and overall performance of MWCNT/heat transfer oil nanofluid flow inside vertical helically coiled tubes, International Journal of Thermal Sciences, 40, pp. 103-111

6. Ito H., 1959, Friction factors for turbulent flow in curved pipes, ASME Journal of Basic Engineering, 81, pp. 123-134

7. Mishra P., Gupta S.N., 1979, Momentum transfer in curved pipes 1, Newtonian fluids, Industrial Engineering Chemical Processes Design and Development, 18, pp. 130-137

8. Xin R.C., Awwad A., Dong Z.F., Ebadian M.A., 1996, An investigation and comparative study of the pressure drop in air-water two-phase flow in vertical helicoidal pipes, International Journal of Heat Transfer, 39 (4), pp. 735-743

9. Campolumghi F., Cumo M., Ferrari G., and Palazzi G., 1977, Full scale tests and thermal design for coiled once-through heat exchangers, American Institute of Chemical Engineers Symposium Series, 73, pp. 215-222

10. Nariai H., Kobayashi M., Matsuoka T., 1982, Friction pressure drop and heat transfer coefficient of two-phase flow in helically coiled tube once-through steam generator for integrated type marine water reactor, Journal of Nuclear Science and Technology, 19 (11), pp. 936-947

11. Kang H.J., Lin C.X., Ebadian M.A., 2000, Condensation of R134a flowing inside helicoidal pipe, International Journal of Heat and Mass Transfer, 43 pp. 2553-2564

12. Han J.T., Lin C.X., Ebadian M.A., 2005, Condensation heat transfer and pressure drop characteristics of R-134a in an annular helical pipe, International Communications in Heat and Mass Transfer, 32, pp. 1307-1316

13. Kahani M., Heris S.Z., Mousavi S.M., 2013, Comparative study between metal oxide nanopowders on thermal characteristics of nanofluid flow through helical coils, Powder Technology, 246, pp. 82-92

14. Wu Z., Wang L., Sunden B., 2013, Pressure drop and convective heat transfer of water and nanofluids in a double-pipe helical heat exchanger, Applied Thermal Engineering, 60, pp. 266-274

15. Mandal S.N., Das S.K., 2003, Gas-liquid flow through coils, Korean Journal of Chemical Engineering, 204(4), pp. 624-630

16. Murai Y., Yoshikawa S., Toda S., Ishikawa M., Yamamoto F., 2006, Structure of airwater two-phase flow in helically coiled tubes, Nuclear Engineering and Design, 236, pp. 94-106 
17. Saffari H., Moosavi R., Gholami E., Nouri N.M., 2013, The effect of bubble in the pressure drop reduction in helical coil, Experimental Thermal and Fluid Science, 51, pp. 251-256

18. Kannadasan N., Ramanathan K., Suresh S., 2012, Comparison of heat transfer and pressure drop in horizontal and vertical helically coiled heat exchanger with $\mathrm{Cu} /$ water based nanofluids, Experimental Thermal and Fluid Science, 42, pp. 64-70

19. Nouri N.M., Motlagh S.Y., Navidbakhsh M., Dalilhaghi M., Moltani A.A., 2013, Bubble effect on pressure drop reduction in upward pipe flow, Experimental Thermal and Fluid Science, 44, pp. 592-598

20. Awwad A., Xin R.C., Dong Z.F., Ebadian M.A., Soliman H.M., 1995, Measurement and correlation of the pressure drop in air-water two-phase flow in horizontal helicoidal pipes, International Journal of Multiphase Flow, 21 (4), pp. 607-619

21. Narrein K., Mohammed H.A., 2013, Influence of nanofluids and rotation on helically coiled tube heat exchanger performance, Techmochimica Acta, 564, pp. 13-23

22. Jamshidi N., Farhadi M., Sedighi K., Domeiry G., 2012, Optimisation of design parameters for nanofluids flowing inside helical coils, International Communications in Heat and Mass Transfer, 39, pp. 311-317

23. Sasmito P.A., Kurnia J.C., Mujumdar A.S., 2011, Numerical evaluation of laminar heat transfer enhancement in nanofluid flow in coiled square tubes, Nanoscale Research letters, 6:376

24. Naphon P., Wongwises S., 2006, A review of flow and heat transfer characteristics in curved tubes, Renewable and Sustainable Energy Reviews, 10 (5), pp. 463-490

25. Guo L.J., Feng Z.P., Chen X.J., 2001, Pressure drop oscillation of steam-water twophase flow in a helically coiled tube, International Journal of Heat and Mass Transfer, 44, pp. $1555-1564$

26. Cioncolini A., Santini L., Ricotti M.E., 2008, Subcooled and saturated water flow boiling pressure drop in small diameter helical coils at low pressure, Experimental and Fluid Science, 32 pp. 1301-1312

27. Zhao L., Guo L., Bai B., Hou Y., Zhang X., 2003, Convective boiling heat transfer and two-phase flow characteristics inside a small horizontal helically coiled tubing oncethrough steam generator, International Journal of Heat and Mass Transfer, 46 pp. 47794788

28. Kozeki M., Nariai H., Furukawa T., Kurosu K., 1970, A study of helically coiled tube once-through steam generator, Bull.JSME, 13(66), pp. 1485-1494

29. Elsayed A., Al-dadah R., Mahmoud S., Rezk A., 2014, Numerical investigation of turbulent flow heat transfer and pressure drop of $\mathrm{Al}_{2} \mathrm{O}_{3} /$ Water nanofluid in helically coiled tubes, International Journal of Low-Carbon Technologies, 0, pp. 1-8

30. Aly W., 2014, Numerical study on turbulent heat transfer and pressure drop of nanofluid in coiled tube-in-tube heat exchangers, Energy Conversion and Management, 79, pp. 304-316

31. Mohammed H.A., Narrein K., 2012, Thermal and hydraulic characteristics of nanofluid flow in a helically coiled tube heat exchanger, International Communications in Heat and Mass Transfer, 39, pp. 1375-1383

32. Bi Q.C., Chen T.K., Luo Y.S., Zheng J.X., Jing J.G., Frictional pressure drop of steamwater two-phase flow in helical coils with small helix diameter, in: Chen et al. (Eds.), Proc. Of the $3^{\text {rd }}$ International Symposium on Multiphase Flow and Heat Transfer, vol. 1, Xi' an Jiaotong Univ. Press and Begell House Inc., 1994, pp. 498-505

33. Owhadi A., Bell K.J., Crain Jr. B., 1968, Forced convection boiling inside helically coiled tubes, International Journal of Heat and Mass Transfer, 11, pp. 1179-1793 
34. Lockhart, R.W., Martinelli, R.C.; 1949, Proposed correlation of data for isothermal two-phase two-component flow in pipes, Chemical Engineering Progress, 45, pp. 3948

35. Martinelli R.C., Nelson D.B., 1948, Prediction of pressure drop during forced circulation boiling of water, Transactions of ASME, 70, pp. 695-702

36. Chen L., Steam-water two-phase flow frictional pressure drop in straight tubes, in: Chen X. (Ed.), Selected papers of multiphase flow and heat transfer, Paper 7, Xi' an Jiaotong University Press, 1982, pp. 7.1-7.6

37. Guo L., Feng Z., Chen X., 2001, An experimental investigation of the frictional pressure drop of steam-water two-phase flow in helical coils, International Journal of Heat and Mass Transfer, 44, pp. 2601-2610

38. Santini L., Cioncolini A., Lombardi C., Ricotti M., 2008, Two-phase pressure drops in a helically coiled steam generator, International Journal of Heat and Mass Transfer, 51, pp. 4926-4939

39. Ruffell A.E., The application of heat transfer and pressure drop data to the design of helical coil once-through boilers, Symposium on multi-phase flow systems, University of Strathclyde, Institute of Chemical Engineering Symposium Series, 38, Paper 15

40. Unal H.C., van Gasselt M.L.G., van't Vertlaat P.M., 1981 Dryout and two-phase flow pressure drop in sodium heated helically coiled steam generator tubes at elevated pressures, International Journal of Heat and Mass Transfer, 24, pp. 285-298

41. Chen X.J., Zhou F.D., 1981, An investigation of flow pattern and frictional pressure drop characteristics of air-water two-phase flow in helical coils, in: Proceedings of the Fourth Miami International Conference on Alternate Energy Sources, pp. 120-129

42. Guo L.J., Chen S.K., Zhang Z.P., Correlation for predicting pressure drop of single and two-phase flow through horizontal helically coiled tubes, in: Proceedings of the Third International Symposium on Multiphase Flow and Heat Transfer, Xi'an, China, 1994, pp. 514-521

43. Kubair V.G.,1986, Heat transfer to multiphase flow in coiled pipes, Heat Transfer, C.L. Tien et al. (Ed.), Proceedings of the 8th International Heat Transfer Conference, San Francisco USA, 5, pp. 2355-2360

44. Ju H., Huang Z., Xu Y., Duan B., Yu Y., 2001, Hydraulic performance of small bending radius helical coil-pipe, Journal of Nuclear Science and Technology, 38 (10), pp. 826831

45. Tong L.S., Weisman J., 1996, Thermal analysis of pressurised water reactors. $3^{\text {rd }}$ edition, American Nuclear Society

46. Cui W., Li L., Xin M., Jen T.C., Chen Q., Liao Q., 2006, A heat transfer correlation of flow boiling in micro-finned helically coiled tube, International Journal of Heat and Mass Transfer, 49, pp. 2851-2858

47. Aria H., Akhavan-Behabadi M.A., Shemirani F.M., 2012, Experimental Investigation of flow boiling heat transfer and pressure drop of HFC-134a inside a vertical helically coiled tube, Heat Transfer Engineering, 33(2), pp. 79-86

48. Elsayed, A.M., Al-Dadah R.K., Mahmoud S., Rezk A., 2012, Investigation of flow boiling heat transfer inside small diameter helically coiled tubes, International Journal of Refrigeration, 35, pp. 2179-2187

49. Wongwises S., Polsongkram M., 2006a, Evaporation heat transfer and pressure drop of HFC-134a in a helically coiled concentric tube-in-tube heat exchanger, International Journal of Heat and Mass Transfer, 49, pp. 658-670

50. Laohalertdecha S., Wongwises S., 2010, The effects of corrugation pitch on the condensation heat transfer and pressure drop of R-134a inside horizontal corrugated tube, International Journal of Heat and Mass Transfer, 53 pp. 2924-2931 
51. Kim J.W., Kim J.H., Seo S.K., Kim J.H., Kim J.S., 2000, Characteristics of heat transfer and pressure drop of R-22 inside an evaporating tube with small diameter helical coil, Transactions of the Korean Society of Mechanical Engineers Series, B24 (5), pp. 699708

52. Lin C.X., Ebadian M.A., 2007, Condensation heat transfer and pressure drop of R-134a in annular helicoidal pipe at different orientations, International Journal of Heat and Mass Transfer, 50 pp. 4256-4264

53. Scott Downing R., Kojasoy G., 2002, Single and two-phase pressure drop characteristics on miniature helical channels, Experimental Thermal and Fluid Science, 26 pp. 535-546

54. Wongwises S., Polsongkram M., 2006b, Condensation heat transfer and pressure drop of HFC-134a in a helically coiled concentric tube-in-tube heat exchanger, International Journal of Heat and Mass Transfer, 49, pp. 4386-4398

55. Han J.T., Lin C.X., Ebadian M.A., 2005, Condensation heat transfer and pressured drop characteristics of R-134a in an annular helical pipe, International Communications in Heat and Mass Transfer, 32, pp. 1307-1316

56. El-Sayed Mosaad M., Al-Hajeri M., Al-Ajmi R., Koliub A.M., 2009, Heat transfer and pressure drop of R-134a condensation in a coiled, double tube, Heat Mass Transfer, 45 pp. 1107-1115

57. Fsadni A.M., Whitty J.P.M., 2016, A review of the two-phase heat transfer characteristics in helically coiled tube heat exchangers, International Heat and Mass Transfer, 95, pp. 551-565

58. Rippel G.R., Edit C.M., Jordan H.B., 1966, Two-phase flow in a coiled tube, Industrial and Engineering Chemistry Process Design and Development, 5 (1) pp. 32-39

59. Banerjee S., Rhodes E., Scott D.S., 1969, Studies on cocurrent gas-liquid flow in helically coiled tubes, The Canadian Journal of Chemical Engineering, 47, 445-453

60. Awwad A., Xin R.C., Dong Z.F., Ebadian M.A., Soliman H.M., 1995, Flow patterns and pressure drops in air/water two-phase flow in horizontal pipes, Journal of Fluids Engineering, 117(4), pp. 720-726

61. Xin R.C., Awwad A., Dong Z.F., Ebadian M.A., 1997, An experimental study of singlephase and two-phase flow in annular helicoidally pipes, National Heat Transfer Conference, 8, pp. 11-17

62. Vashisth S., Nigam K.D.P., 2007, Experimental Investigation of Pressure Drop during Two-Phase Flow in a Coiled Flow Inverter, Industrial \& Engineering Chemistry Research, 46 (14) pp.5043-5050

63. Chen X., Guo L., 1999, Flow patterns and pressure drop in oil-air-water three-phase flow through helically coiled tubes, International Journal of Multiphase Flow, 25, pp. 1053-1072

64. Czop V., Barbier S., Dong S., 1994, Pressure drop, void fraction and shear stress measurements in an adiabatic two-phase flow in a coiled tube, Nuclear Engineering and Design, 149 pp. 323-333

65. Biswas A.B., Das S.K., 2008, Two-phase frictional pressured drop of gas-nonNewtonian liquid flow through helical coils in vertical orientation, Chemical Engineering and Processing, 47 pp. 816-826

66. Mazzitelli I., Lohse D., Toschi F., 2003, The effect of micro bubbles on developed turbulence, Physics of Fluids, 15(1), L5

67. Bao-Guo C., Nan-Sheng L., 2011, Direct numerical simulations of turbulent channel flows with consideration of the buoyancy effect of the bubble phase, Journal of Hydrodynamics, 23 (3), pp. 282-288 
68. Kasturi G., Stepanek J.B., 1972, Two-phase flow-I. Pressure drop and void fraction measurements in concurrent gas-liquid flow in a coil, Chemical Engineering Science, 27 pp. $1871-1880$

69. Whalley P.B., 1980, Air-water two-phase flow in a helically coiled tube, International Journal of Multiphase flow, 6(4), pp. 345-356

70. Rangacharyulu K., Davies G.S., 1984, Pressure drop and holdup studies of air-liquid flow in helical coils, The Chemical Engineering Journal, 29 pp. 41-46

71. Chisholm D., 1967, Pressure gradients during the flow of incompressible two-phase mixtures through pipes, Venturis and orifice plates, Chemical Engineering, 12(9), pp. 1368-1371

72. Fakoor-Pakdaman M., Akhavan-Behabadi M.A., Razi P., 2013, An empirical study on the pressure drop characteristics of nanofluid flow inside helically coiled tubes, International Journal of Thermal Sciences, 65, pp. 206-213

73. Hashemi S.M., Akhavan-Behabadi M.A., 2012, An empirical study on heat transfer and pressure drop characteristics of $\mathrm{CuO}$-base oil nanofluid flow in a horizontal helically coiled tube under constant heat flux, International Communications in Heat and Mass Transfer, 39, pp. 144-151

74. Mukesh Kumar P.C., Kumar J., Sendhilnathan S., Tamilarasan R., Suresh S., 2014, Heat transfer and pressure drop of $\mathrm{Al}_{2} \mathrm{O}_{3}$ nanofluid as coolant in shell and helically coiled tube heat exchanger, Bulgarian Chemical Communications, 46(4) pp. 743-749

75. Suresh S., Chandrasekar M., Chandra Sekhar S., 2011, Experimental studies on heat transfer and friction factor characteristics of $\mathrm{CuO} /$ water nanofluid under turbulent flow in a helically dimpled tube, Experimental Thermal and Fluid Science, 35, pp. 542-549

76. Seban R.A., Mclaughlin E.F., 1963, Heat transfer in tube coils with laminar and turbulent flow, International Journal of Heat and Mass Transfer, 6, pp. 387-395

77. Kahani M., Zeinali Heris S., Mousavi S.M., 2013, Effects of curvature ratio and coil pitch spacing on heat transfer performance of $\mathrm{Al}_{2} \mathrm{O}_{3} /$ Water nanofluid laminar flow through helical coils, Journal of Dispersion Science and Technology, 34:12, pp. 17041712

78. Akbaridoust F., Raksha M., Abbassi A., Saffar-Avval M., 2013, Experimental and numerical investigation of nanofluid heat transfer in helically coiled tubes at constant wall temperature using dispersion model, International Journal of Heat and Mass Transfer, 58, pp. 480-491

79. Rabienataj Darzi A.A., Farhadi M., Sedighi K., Aallahyari S., Aghajani Delavar, 2013, Turbulent heat transfer of $\mathrm{Al}_{2} \mathrm{O}_{3}$ - water nanofluid inside helically corrugated tubes: Numerical Study, International Communication in Heat and Mass Transfer, 41, pp. 6875

80. Moraveji M.K., Hejazian M., 2014, CFD examination of convective heat transfer and pressure drop in a horizontal helically coiled tube with $\mathrm{CuO} / \mathrm{Oil}$ base nanofluid, Numerical Heat Transfer, Part A: Applications, 66 pp. 315-329

81. Fsadni A.M., Ge Y.T., Lamers A.G., 2011, Measurement of bubble detachment diameters from the surface of the boiler heat exchanger in a domestic central heating system, Applied Thermal Engineering, 31, (14-15), pp. 2808-2818 